\title{
Invigorating the Content in Social Embeddedness: An Ethnography of Life Insurance Transactions in China ${ }^{1}$
}

\author{
Cheris Shun-ching Chan \\ University of Hong Kong
}

\begin{abstract}
Based on more than 14 months' ethnographic research in China, this article brings in culture and symbolic interactionism to understand the social embeddedness of economic transactions. First, an analytic frame linking tie strengths to defining principles, relational properties, and interactions is constructed and applied to changes in life insurance transactions in China. The data suggest that strong tie transactions were common until the economic gains of the sellers were made public. The author argues that the ethical-affective principle that defines strong ties and the high intensity of trust, affection, and asymmetric obligation that constitute these ties make them a double-edged sword for economic transactions. Instead, ties with midrange or weak strength are more effective because of their relational complementarity (although direct economic exchanges may take place among strong ties under extreme institutional or contingency conditions). The author also reveals that dramaturgical interactions, through which economic actors exercise their agency, are an integral part of embedded transactions.
\end{abstract}

Mark Granovetter's (1973, 1974) strength-of-weak-ties theory has stimulated volumes of research on the structural embeddedness of economic activities (Bonacich 1987; Baker 1990; Burt 1992; Romo and Schwartz

${ }^{1}$ I am indebted to all the informants who made my fieldwork possible. In addition,
Gary Fine, Bruce Carruthers, Wendy Griswold, Charles Ragin, and Bobai Li deserve
special thanks for their unfailing support to this project. I am grateful to Gary Fine,
Yanjie Bian, Jeff Manza, Ching Kwan Lee, Ethan Michelson, Peer Fiss, John Markoff,
Kathleen Blee, Debbie Gould, Assata Richards, Xiaodan Zhang, and the AJS reviewers
for helpful comments on the earlier versions of this article. Part of this article was
presented at the annual meeting of the American Sociological Association in Atlanta
in August 2003. The research on which this article is based was funded by the Social
Science Research Council, the Center for International and Comparative Studies at
Northwestern University, and the Asian Studies Center at the University of Pittsburgh.

(C) 2009 by The University of Chicago. All rights reserved. 0002-9602/2009/11503-0002\$10.00

712 AJS Volume 115 Number 3 (November 2009): 712-54 
1995). Innovative methodological techniques, including the use of mathematical steps for algorithm building, have advanced social network analysis to a rigorously formalized scientific field (White 1981; Watts and Strogatz 1998). Network analysis, by definition, is formalistic and interested only in patterns of relations, not in substantive content (Burt 1986). This, however, prompts the worry that the sophistication of structural analytical techniques has unintentionally produced a "black box" problem in network analysis (Emirbayer and Goodwin 1994). Swedberg (1997) laments that social embeddedness has been reduced to network analysis that is sterile and devoid of substance (see also White 1992). Prominent economic sociologists earnestly call for bringing the content of social ties back in (Stinchcombe 1990; Powell and Smith-Doerr 1994; Gerlach and Lincoln 1998), particularly culture and meaning that define, realize, and perform the relational content of embeddedness (Zelizer 1988; DiMaggio 1992; White 1992; Emirbayer and Goodwin 1994; Biggart and Beamish 2003). This article brings culture, meaning, and interaction to the forefront by focusing on the relational content of social ties.

Granovetter (1973) acknowledged early on that both concrete personal relations and structures (or networks) of such relations are equally important. In a less cited article, he elaborates and consolidates the concept of embeddedness by distinguishing relational and structural embeddedness (Granovetter 1990). While structural embeddedness is defined by networks of interpersonal relations, relational embeddedness is defined by concrete interpersonal relationships among individual economic actors, the meaning of the relational category, and the history of interactions and consequent mutual expectations. Relational embeddedness, Granovetter (1990) notes, has a direct effect on economic action and deserves the same amount of attention as its structural counterpart. Fortunately, an increasing number of scholars have been putting relational embeddedness at the center of attention. Norms, trust, obligations, and expectations have been integrated into the embeddedness literature (e.g., Wellman and Wortley 1990; Gerlach 1992; Davis and Greve 1997; Podolny and Baron 1997; Brinton and Nee 1998; Wellman 1999; Uzzi and Lancaster 2003). Harrison White, who was formerly a leading figure in structural determinism, has more recently claimed a central role for meanings in network analysis. A social network, in his words, is "a network of meanings" (White 1992, p. $65)$.

I also thank the Centre of Asian Studies at the University of Hong Kong for its facilities and the International Institute at the University of California, Los Angeles, for its generous fellowship, which facilitated the completion of this article. Direct correspondence to Cheris Shun-ching Chan, Department of Sociology, Room 1217 K. K. Leung Building, University of Hong Kong, Pokfulam Road, Hong Kong. Email: cherisch@hku.hk 
American Journal of Sociology

Based on an ethnographic case study of life insurance transactions in China, this article presents a microscopic picture of how relational content affects economic exchanges. By relational content, I mean the defining principles and relational properties that qualify different tie strengths and the interactions between actors in those ties. The theoretical frame is broadly informed by relational embeddedness that focuses on the substantive content of social relations (Dore 1983; Sako 1992; Uzzi 1997; Uzzi and Lancaster 2003), cultural economic sociology that highlights meanings in defining different types of relationships (Biggart 1989; Zelizer 1996, 2005), social exchange theory that gives insights into the role of reciprocity in economic exchanges (Gouldner 1960; Homans 1974), and symbolic interactionism, particularly Goffman's $(1959,1967,1983)$ interaction order that focuses on the strategic capacities of individuals in different structural positions. While most embeddedness studies are based on quantitative methods (Powell [1985] and Uzzi [1997] offer two exceptional examples), this study takes a rather different approach. It applies not only interviews but year-long participant observations in the natural settings in which economic transactions occur. Based on process-oriented field research, this article explores the dynamics through which tie strengths are linked to direct economic transactions in a non-Western context.

Selling and buying life insurance belongs to a kind of negotiated direct economic exchanges in which actors engage in explicit bargaining to reach a bilateral agreement that economically benefits both parties (Blau 1964; Homans 1974; Emerson 1981; Molm, Peterson, and Takahashi 1999). In contrast to "negotiated exchanges" are "reciprocal exchanges" in which actors perform a beneficial act for another without knowing whether, when, and how the other will reciprocate (Molm et al. 1999). In commercial life insurance transactions, sellers and buyers negotiate over the prices and terms of coverage through potential buyers' shopping around and sellers' calculation of profitability. Negotiation takes place because one party's sizable gains can be another party's losses. Therefore, life insurance transactions represent a common form of economic exchange in a monetary market economy. In addition, it is a case in which social embeddedness is particularly high. The public resistance to the commensurating logic of life insurance (Zelizer 1979; Espeland and Stevens 1998) requires life insurance firms to deploy aggressive personal solicitation through sales agents' strategic interactions with prospects (Oakes 1990; Leidner 1993). This highly embedded nature of life insurance sales provides rich data for the possibility of characterizing different forms of socially embedded exchanges. Conducting the research in mainland China, where the life insurance industry is just in its emergent stage, further supplies rich nuances for an indicative, dynamical dissection.

Commercial life insurance is emerging in China at the intersection of 
the country's transformation from a socialist to a market economy and the global expansion of the insurance industry. Although many European and North American life insurers entered China during the imperialist expansions of the late 19th century, the life insurance industry generally failed to take hold in mainland China (Wu and Zheng 1993). Then, during the Maoist regime and early post-Maoist years that spanned an entire generation (the 1950s to the 1980s), commercial life insurance essentially disappeared. It was not until 1992 that commercial life insurance appeared in the People's Republic of China for the first time, when American International Assurance Limited (AIA), a subsidiary of American International Group Limited, arrived in Shanghai. Local resistance to life insurance as a new concept and a new commodity was evident (Chan 2009), but AIA pioneered a proactive personal and commission-based agency sales system to market this new commodity. Within a few years, a number of domestic and Sino-foreign joint-venture life insurance companies were established, first in Shanghai and subsequently in other major cities. They all adopted an aggressive, commission sales method to create a life insurance market.

While the commission sales system was new to the local population, using personal relations to achieve economic transactions was not. The pervasiveness and dominance of guanxi (interpersonal relations or connections) in Chinese economies have been well documented by sociologists and anthropologists (Walder 1986; Bian 1994, 1997; Yang 1994; Wank 1996; Yan 1996; Wong and Salaff 1998). For life insurance sales, the role of guanxi is indisputably crucial. However, an empirical puzzle over the use of guanxi for life insurance sales was observed. Life insurance transactions among intimate guanxi were prevalent in the early stages when life insurance was first introduced. Toward the end of the 1990s and the early 2000s, however, sales agents avoided selling directly to close friends and relatives. Instead, they spent most of their time and energy selling themselves to impress acquaintances or building friendships with existing clients for referrals. Thus, there was a shift in which life insurance transactions occurred in relation to the strengths of ties between sellers and buyers. They moved from strong ties to moderate and weak ties. Why did such a shift take place?

A plausible explanation based on the structural aspect of the strengthof-weak-ties hypothesis is that the agents might have exhausted their intimate circles and then needed to extend the pool of potential clients by reaching distant acquaintances and clients' networks (Granovetter 1973, 1974; Baker 1990; Burt 1992). Undoubtedly, salespersons cannot solely rely on their intimate circles; at some point they will need to extend their pool of potential clients. However, this explanation is inadequate. First, the problem of agents exhausting existing intimate circles had not 
occurred. Note that the annual turnover rate of insurance agents in China was as high as $80 \%{ }^{2}$ As the agents did not form a fixed pool of people, there were always new agents who could bring in new intimate social circles. More important, if the agents simply needed to extend the pool of prospects, they could do so in addition to selling to close intimates. Why, then, did the agents begin avoiding selling to close friends and relatives? Furthermore, why did this tendency begin at the end of the 1990 s but not earlier?

My findings indicate that when life insurance as a commodity is new and alien to a population, when market regulations have not yet been established, and, most important, when the economic interests of the sales agents are covert, transactions take place among strong ties in which trust, affection, and asymmetric obligation are the core relational properties. However, when the economic gains of the sales agents are visible and obvious, their motives for selling the commodity then appear to be blatantly self-interested. A self-interested motive for interacting with close intimates violates the ethical-affective principle that defines a close relationship. This violation deters both parties from entering into a direct transaction for the sake of preserving their existing relationship. My argument is that strong ties are double-edged for direct economic transactions. They are inherently a less desirable relational category for economic transactions, not only because of their structural limitations but also because the cultural rules that define and govern strong ties are uncongenial to transactions that involve explicit bargaining of economic interests. Ties with midrange to weak strength are better for economic transactions because of their relational complementarity. Their relatively balanced composition of relational properties and mixed defining principles results in content flexibility that leaves more room for legitimating economic exchanges motivated by self-interest. However, under certain extreme institutional or contingency conditions, economic transactions may have to take place only in strong ties in which trust, affection, and obligation are facilitative. Regardless of where the embedded transactions take place, dramaturgical efforts are required, especially on the parties who seek exchanges. I argue that it is through dramaturgical performances and interactions that individual economic actors exercise their agency to maneuver their relational qualities and structural positions in a network for their economic purposes.

\footnotetext{
${ }^{2}$ No official figure of agents' turnover rate is available. However, almost all managers and senior agents whom I interviewed gave a rather consistent estimate at $80 \%$. This high turnover rate was also found in the insurance industry in the United States. Leidner (1993, p. 95) reported that the average five-year retention rate of sales agents in the insurance industry in the United States was only $18 \%$.
} 
In the sections that follow, I first develop an analytic frame that links tie strengths to their defining principles, relational properties, and expected interactions for economic exchanges. The analytic frame is then applied to characterize the Chinese social relations, guanxi. After a section on method and data collection, I rely on the analytic frame to illustrate the possible explanations for the change in life insurance transactions in relation to the strengths of ties between Chinese sellers and buyers. I analyze how and why three different forms of socially embedded life insurance transactions, namely, reflexive trust, obligation, and personage, take place in different tie strengths under different conditions. I discuss the generalizability of the analysis after an encapsulation of my arguments. The theoretical contributions and limitations of this study, as well as the implications for future research, are discussed in the concluding section.

\section{AN ANALYTIC FRAME: TIE STRENGTHS AND ECONOMIC TRANSACTIONS}

To define tie strengths in terms of their relational content, I propose an analytic frame that draws useful concepts and insights from the literature of social embeddedness, cultural sociology, social exchange theory, and symbolic interactionism. ${ }^{3}$ This analytic frame is based on two postulates as represented in figure 1 .

First, individual actors differentiate among the meanings, operating rules, and boundaries that separate one relation from another (Zelizer 2005). It is postulated that the meanings that define and the operating rules that govern various tie strengths can be marked at points on a continuum between ethical-affective and instrumental-monetary domains. Strong ties are defined by a high degree of affections and ethical obligations. Very weak ties or arm's-length ties, however, are defined by a high degree of instrumental and monetary capacities. Nonetheless, it should be noted that although intimate circles operate primarily in the ethical-affective domain, they serve important instrumental functions. ${ }^{4}$ The meanings and operating principles of different ties, therefore, are not defined by their functions, but rather by culturally and socially acceptable motives (Uzzi 1997, 1999). The stronger the ties are, the more the motives are expected to be altruistic and expressive. Because intimate relationships by definition place demanding claims on moral appropriateness, the boundaries that delineate strong ties are relatively inflexible. However,

\footnotetext{
${ }^{3}$ For a methodological discussion of why analytic frames are preferred for qualitative research, see Ragin (1994, pp. 55-102).

${ }^{4}$ Parents feeding their children and people lending money to close friends are two simple examples of intimate relations serving important instrumental functions.
} 


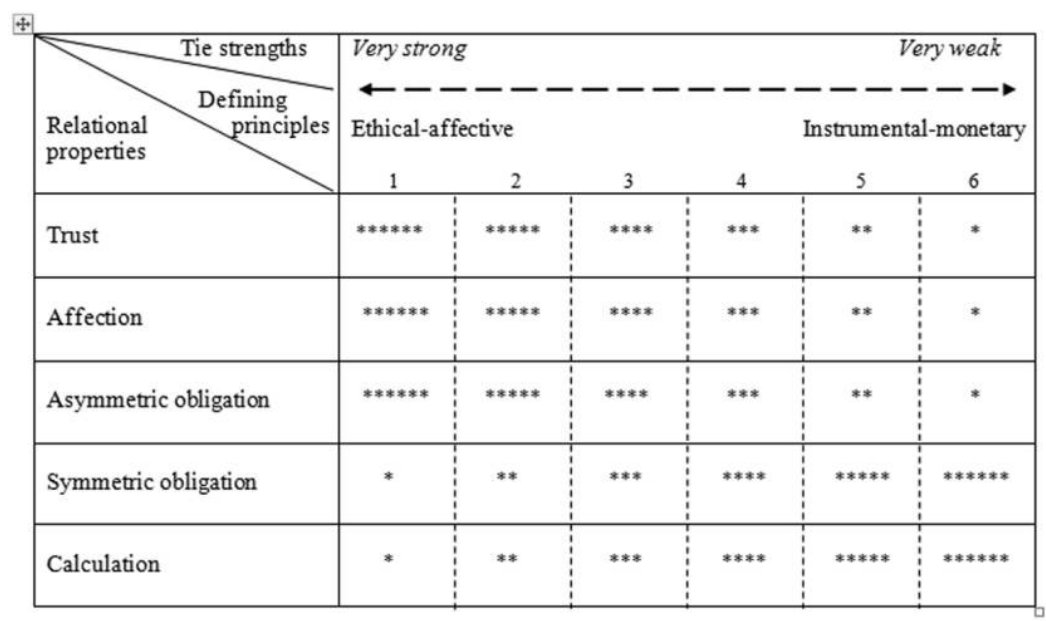

FIG. 1.-An analytic frame linking tie strengths to defining principles and relational properties. The star scores assigned to each cell represent the hypothetical intensity of each relational property in a given tie strength.

the weaker the ties are, the looser the boundaries are when drawing inclusions from exclusions.

A second postulate is that tie strength is a continuous variable (Granovetter 1973; Krackhardt 1992; Guseva 2008) and different degrees of tie strength embody different compositions of the relational properties of trust, affection, asymmetric obligation, symmetric obligation, and calculation. Figure 1 presents a hypothetical model that links the intensity of each relational property to a particular strength of tie. This model posits that the stronger the social ties are, the more they bear the elements of trust, affection, and asymmetric obligation and the less they bear elements of symmetric obligation and calculation. The social network and social exchange literature has long recognized that mutual trust and affection are essential elements of close and intimate relationships. The closer a relationship is, the stronger the sense of trust and the feelings of affection are between members (Wellman and Wortley 1990; Molm, Takahashi, and Peterson 2000). Another key element that characterizes and reproduces strong ties is asymmetric obligation that defines the norm of reciprocity. According to Gouldner (1960), reciprocity connotes that each party has rights and obligations, and one party's right is in turn the other party's obligation. Unlike trust and affection that can be simultaneously mutual, reciprocity is an exchange of rights and obligations that often involves a time lag. Gouldner argues that indebtedness, created by the time lag between Ego's provision of a gratification and Alter's repayment, is a 
kind of "moral cement" that reproduces and stabilizes social relations (p. 175). Generally, the closer a relationship is, say a parent-child relationship, the longer the time lag is allowed and expected for exchange of rights and obligations. ${ }^{5}$ This means that the delivery of obligations in an intimate relationship is often asymmetric. However, an immediate exchange of rights and obligations is expected in impersonal transactions that take place among arm's-length ties. Apparently, many social and economic exchanges take place in relations that fall in between parent-child and arm's-length ties. But we can expect that asymmetric obligation is a constituent element of strong ties whereas symmetric obligation is an important element of weak ties. Finally, the calculation of costs and benefits that are based on self-interest is more likely to be present among weak ties. With strong ties, too much instrumental calculation debases the altruistic and expressive meanings attached to close and intimate relationships.

To use this analytic frame to project which kinds of relations better facilitate economic transactions, I find Uzzi's concept of complementarity useful. In his study of firms seeking financing, Uzzi (1999) finds that networks with a mix of both embedded and arm's-length ties are the optimal type of networks for firms' performance, since networks as such are able to synthesize the benefits of different types of ties into what he called "network complementarity." On the basis of this complementarity logic, we can project that tie strengths with relatively balanced composition of various relational properties are the best category of ties for dyadic direct economic transactions. Ties as such are able to achieve relational complementarity by synthesizing the benefits of different relational properties. Then, the best types of relations for economic exchanges are those in the middle (cols. 3 and 4 in fig. 1). Former schoolmates, colleagues, neighbors, ordinary friends, and distant relatives are some examples. These ties, with midrange strength, allow calculative and economically driven exchanges and yet still possess a certain degree of trust, affection, and obligation. Relatively fair exchanges are expected, though a less precise calculation is required. However, the strongest ties (col. 1 in fig. 1), defined by an ethical-affective principle, are generally not the best type for negotiated economic exchanges. While the presence of a strong sense of trust can certainly reduce transaction costs (Granovetter 1985; Uzzi 1996; DiMaggio and Louch 1998; Sako and Helper 1998; Guseva 2008), the elements of affection and asymmetric obligation are unfavorable to instrumental, self-interest-oriented economic transactions.

${ }^{5}$ For example, a parent typically delivers asymmetric obligations to a child until the child has grown up. The child may (or may not) return the indebted favor to the parent when the parent is old and needs her or his care. 
The weakest ties (col. 6 and beyond in fig. 1) are not the best category for business deals either. The lack of trust and the constant calculation of costs and benefits in those ties are likely to induce higher transaction costs. This is especially the case in an institutional environment in which formal law and regulations that warrant fair transactions are underdeveloped or ineffective (see Guseva and Rona-Tas [2001] and Guseva [2008] on Russia and Peng [2004] on China).

The above projection, however, is based on a static model. When economic actors and their interactions are integrated into the analytic frame, economic transactions may take place in very strong ties and very weak ties with dramaturgical strategies. In Goffman's (1959) terms, for an Ego to influence an Alter's definition of the situation, the former has to give off a certain impression so that she or he can control the behaviors of the latter. Goffman's interaction theories are particularly useful for examining the "black box" between individual actors' structural positions and economic outcomes. In line with the embeddedness account is Goffman's rejection of an atomized cost-benefit analysis and focus on the importance of "one's place in the social structure" for understanding actors' interactions (1983, p. 6). With Goffman's insights added into the framework, sellers can hide or downplay their economic gains when dealing with those in strong ties so as to transform the negotiated exchanges to appear as reciprocal ones. Alternatively, they can cultivate a higher degree of trust, affection, and sense of obligation with weakly tied potential buyers in order to smooth transactions.

To what extent can this analytic frame be applied to places with different cultural and institutional settings? Hamilton (1996) gravely questions the validity of applying theoretical tools developed from Western networks to Asian networks. He contrasts the Asian networks with Western ones, suggesting that the organizing principles of the former are based on norms, relations, hierarchy, and substance whereas those of the latter are based on voluntarism and individualism. While I agree with his characterization of the organizing principles of the Asian networks, I cannot agree that the Western networks are in sharp contrast. As Macneil (1985) points out, the assumption of voluntaristic choice in contracting, even in the most market-oriented American context, is false. The relational norms that enforce obligation and "coerce" people into contractual arrangements are evident in market-oriented economies (pp. 503-4). I believe that the Western networks appear to be voluntaristic and individualistic partly because of the scarcity of thick descriptions of the normative and relational dynamics in conventional network analysis. Macaulay's (1963) classic piece on the enforcing power of norms, expectations, and reputations and the recent efforts to return to study networks' substances all suggest that mutual trust, affection, and the norm of reciprocity have significant im- 
pacts on people's market behaviors across nations (Dore 1983; Gerlach 1992; Krackhardt 1992; Uzzi 1997, 1999; Sako and Helper 1998; Guseva and Rona-Tas 2001). Thus, I propose that the above analytic frame can be applied to both Western and Asian contexts. The defining principles and the direction of intensity of the relational properties in different tie strengths are universal. In other words, trust, affection, and asymmetric obligation must be higher in strong ties than in weak ties and symmetric obligation and calculation must be higher in weak ties than in strong ties. However, the level of intensity of the relational properties in each box in figure 1 may vary across spatial and temporal contexts. Hence, applying the analytic frame to a Chinese context requires some modifications to the model.

\section{APPLYING THE ANALYTIC FRAME TO THE CHINESE GUANXI}

Scholarly debates over the nature of guanxi and its role in economic life are constellated along three axes. First, do strong ties work better than weak ties in China because of unique political and institutional arrangements (Bian 1997; Lin 2002; Wank 2002)? Second, is the importance of guanxi in economic life declining, persistent, or intensified in conjunction with China's economic reform (Gold 1985; Guthrie 1998; Lin 2001; Bian 2002; Hanser 2002)? Finally, is the characteristic and basic nature of Chinese guanxi unique or universal (Hwang 1987; Lin 2001; Wellman, Chen, and Dong 2002)? This article engages in these debates as follows.

First, instead of challenging or supporting the strong-ties-matter hypothesis, this article explores under what conditions strong ties facilitate or impede direct economic transactions, and why. Bian and Ang's (1997) comparative studies of job mobility in Singapore and Tianjin (a city in northern China) find that ties of medium strength operate most effectively in both cities. They call for future research on the meanings and implications of social ties of medium strength to understand the limits of ties that are either too close or too distant. This article certainly has implications in this respect.

Second, Guthrie $(1998,1999)$ finds that the rational-legal model of business practices has been gaining legitimacy in urban China, and as a result, there has been a decline in the use of personal guanxi in business transactions. He argues that increasing institutionalization leads to declining significance of guanxi in the Chinese economy. This study finds a shift in where transactions take place among strong ties versus moderate and weak ties. At first sight this shift may seem to support the hypothesis of the declining significance of guanxi. However, since embeddedness persists in a market economy and the effect of social relations does not disappear 
in markets in which uncertainty is low (Granovetter 1985; Uzzi and Lancaster 2004), the increasing marketization and institutionalization in China have not diminished the role of guanxi, though its manifestations vary. As there are many different types of guanxi (Walder 1986; Wank 1996; Michelson 2007), the declining use of one particular type does not indicate the decreasing importance of guanxi per se. More important, as the data will show, turning away from strong ties in making transactions is precisely what preserves the significant meanings of intimate guanxi. When turning to loose ties for transactions, the sales agents have been making an effort to create closer relationships with prospects in order to succeed. They would not have to do so if guanxi were declining in importance.

As to what extent Chinese guanxi is unique or universal, this article takes the position that there is nothing inherently unique about guanxi. Lin (2001) points out that the sentimental basis, obligatory exchanges, and instrumental uses of guanxi, in fact, demonstrate only traits of social exchanges in Homans's theory. Therefore, the mechanisms through which guanxi of different types impedes or facilitates economic exchanges among the Chinese should not be assumed qualitatively distinct. Nonetheless, the structure of Chinese guanxi and aspects of its content are distinguishable from the conventional features of social networks in Anglo-Saxon societies. These unique features of guanxi led me to modify the analytic frame for the Chinese case, as represented in figure 2. Note that the intensity (represented by the star scores) of each relational property in this figure may be different from that in figure 1.

The modified analytic frame is derived largely from existing literature about Chinese guanxi. First, I rely on the prominent Chinese sociologist Xiaotong Fei's framework, which has been most widely adopted by sinologists to characterize the general pattern of Chinese social relations (Hamilton 1996; Bian 1997; Zhao 1998; Peng 2004). According to Fei ([1948] 1992), the general pattern of Chinese social relations is characterized as a "differential mode of association." It is analogized as the circles that appear on the surface of a lake when a rock is thrown into it. In other words, the Chinese guanxi are structured in a nested concentric pattern with the Ego in the center. Layers of concentric circles extending from the center represent different categories of relations to the Ego in a descending order of intimacy. The degree of closeness and intimacy specifies the degree of trustworthiness, intensity of sentiment, and type of obligation. The concentric and hierarchical character of Chinese guanxi is indicated by the quarters of circles in figure 2 .

Second, I draw on David Wank's categorization of Chinese guanxi. According to Wank (1996), the degree of intimacy in Chinese guanxi descends from those that are ascribed to acquired personal relations and 


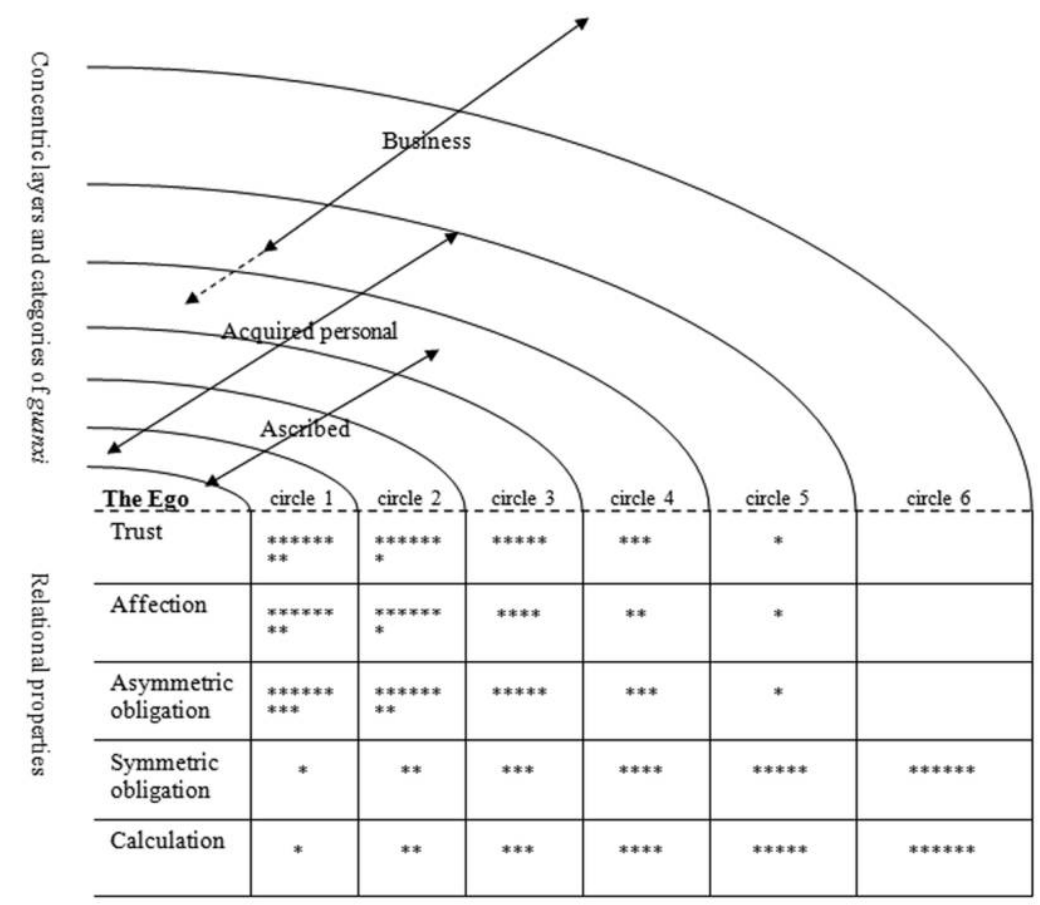

FIG. 2.-The pattern and categories of Chinese guanxi and their relational properties. The star scores in certain cells deviate from those in figure 1 since they represent the intensity of the relational properties in Chinese guanxi as opposed to the hypothetical model.

finally to business relations. Ascribed relations are those produced by birth. They are blood ties, or directly related kin. Acquired personal relations refer to ties formed by shared experiences prior to any business exchanges. Business relations are those personal ties forged after the onset of deals for commercial ends. Despite the argument that postreform China has been shifting from a group-based to a network-based society (Gold 1989; Lin 2001), kinship continues to play a particularly important role in Chinese business practices (Peng 2004). In contrast to Wellman and Wortley's (1990) findings that extended kin in Canadian communities are the least likely of all network members to provide social or financial support, the extended kin in Chinese societies are often the source of financial support that is provided on the basis of need. ${ }^{6}$ Therefore, blood

${ }^{6}$ For example, it has been common for people who live in a more affluent region, say Hong Kong, to send remittances to distant relatives in mainland China, including those whom they rarely see or have never met, to fulfill the asymmetric obligation of the proverb "blood is thicker than water." I observed these situations in Hong Kong from the 1970 s to the early 2000 s. 
ties in the Chinese guanxi hierarchy often belong to the strong tie category even though contacts between members may be infrequent. Acquired personal relations can be as intimate as ascribed relations if they are spousal relations or are characterized as fictive kin (Peng 2004). The hierarchical order of ascribed, acquired personal, and business relations in terms of their closeness to the Ego is shown in figure 2. The dotted arrow extending from business relations denotes the possibility of turning business relations into personal friends, and yet they are still different from those friends acquired prior to business exchanges.

Finally, to characterize the intensity of the relational properties in different tie strengths, figure 2 indicates that the level of trust and affection and the demand for asymmetric obligation in Chinese strong ties are more intense than that in the hypothetical model. However, trust, affection, and asymmetric obligation in Chinese weak ties or arm's-length ties are relatively low. Lin (2001) proposes that asymmetric obligation is the most distinct component characterizing Chinese social relations. He observes that it is the asymmetric transaction that makes a relation special and qualified to be what the Chinese refer to as guanxi. Lin's insights are shared by Hwang (1987), who suggests that close ties in Chinese societies operate according to the principle of need, whereas the principle of equity applies only to distant and impersonal ties. As asymmetric obligation is such a crucial element for distinguishing the closeness of a relation, weak ties have very little of this property. The same logic applies to trust and affection. The family- and kin-centered character of Chinese social relations (Fei 1992; Kao 1996; Wank 1996; Hamilton 1998) gives ascribed social circles and fictive kin friends the privilege of sharing an extraordinary level of trust and affection. In addition, institutional trust in Chinese contexts is found to be embedded in personal trust (Hamilton 1985; Wong 1996; Tang 2005). Therefore, the highly hierarchical distinction between close ties and strangers designates weak ties as relatively low levels of trust and affection.

The projection from the analytic frame in the previous section on the relation between tie strengths and economic transactions can be largely applied to the Chinese case for life insurance sales. What might be distinctive about the Chinese case is that since asymmetric obligation renders a rich symbolic meaning that qualifies the specialty of a guanxi, this element is expected to play an especially critical role in the dynamics of mobilizing and constructing guanxi for economic transactions. Moreover, since blood ties enjoy a special privilege in demanding asymmetric obligation and a taken-for-granted status in trust, the dramaturgical performances in ties with midrange and weak strengths are expected to go in the direction of forging fictive kin. 


\section{ETHNOGRAPHIC METHOD AND DATA COLLECTION}

This article is derived from a study on the making of a life insurance market in urban China. I conducted more than 14 months of ethnographic research in Shanghai between 2000 and 2004, collecting data in three stages. The initial stage took place in the summer of 2000. On the basis of these findings, I selected four life insurance companies representing a wide variety for a subsequent year-long field study during 2001-2 and a follow-up study in the winter of 2004. These companies included a wholly foreign-owned American insurer, AIA; a local insurer that had experienced dramatic growth, Ping An Life Insurance Company of China Limited (Ping An); a seemingly very localized Sino-American joint venture, PacificAetna Life Insurance Company Limited (Pacific-Aetna); and an apparently less localized Sino-German joint venture, Allianz-Dazhong Life Insurance Company Limited (Allianz-Dazhong).

Data were collected through formal and informal interviews, participant observations, and questionnaires and by referencing public documents and insurers' publications. I conducted participant observations in the agency offices of each selected insurer for two to three months, attending training sessions for the agents, joining in morning assemblies, and participating in small group meetings on a regular basis. With the consent of certain agents, I went with them to search for potential buyers, to sell products, and to visit existing clients. ${ }^{7}$ From 2000 to 2004, I observed 46 morning assemblies, 48 small group meetings or gatherings, 28 training sessions, and 43 occasions of agent-client or agent-prospect interactions. A total of 99 sales agents, 44 managerial staff, 96 clients, and 35 prospects in Shanghai were interviewed (see App. table A1 for the profiles of the interviewees). The observations and interviews were supplemented with 179 nonrandom sampled questionnaires (66 from sales agents, 63 from clients, and 50 from prospects). ${ }^{8}$ In addition, I interviewed a total of 13 insurance practitioners in Beijing to assess the generalizability of the Shanghai case to urban China.

\footnotetext{
${ }^{7}$ One limitation of this method was that sales agents were typically reluctant to bring me along when visiting resistant prospects. One agent explicitly said to me that he would feel uneasy using certain strategic sales discourses in my presence. Fortunately, the sales agents shared their stories of dealing with difficult prospects in morning assemblies, group meetings, and training sessions. Although retrospective cognitive processes were involved when they recounted their interactions with the prospects, listening to a number of stories told by different sales agents is a valid and reliable method of obtaining data that are inaccessible to direct observation.

${ }^{8}$ For the sales agents, I distributed the questionnaires to nine different agency offices, including companies other than the four where I conducted participant observations. For the clients and prospects, I distributed the questionnaires to employees of nine different workplaces. The questionnaire respondents do not overlap with the interviewees.
} 
American Journal of Sociology

As the competition among the insurers was very intense during my research period, I made a conscious decision not to tape interviews with sales agents and managerial staff in order to facilitate the greatest degree of honesty. I asked their consent to let me note dates, figures, and names that they mentioned for accuracy purposes. As for clients and prospects, about half of the interviews were tape-recorded with consent. The data analysis was an ongoing process along with the data collection. In identifying "typicality" (Schneiberg and Clemens 2006), for example, the "typical" marketing strategies deployed by sales agents, the "typical" motives for clients' purchase of life insurance, and the "typical" interactions between agents and prospects, I mostly counted the frequency of reported and observed occurrences. Nonetheless, part of the analytical insights come from rare events, such as agents' occasional conflicts with the prospects and clients' complaints about the agents. In addition to my participant observation and interview data, I made extensive use of insurance yearbooks, newspapers, magazines, and insurers' publications and training materials. These documents provided historical information about insurance sales practices and changes they had undergone since the arrival of AIA. Moreover, the oral histories of my interviewees and the community memories of my informants also provided rich historical data. The historical information provided by certain interviewees and informants (e.g., senior managers, senior sales agents, and former insurance practitioners who had already left the industry) was given more weight than information presented by casual observers.

\section{SOCIALLY EMBEDDED TRANSACTIONS IN DIFFERENT TIE STRENGTHS}

The ethnographic data demonstrate that life insurance transactions in China are remarkably socially embedded, and they are embedded in different forms. Three distinguishable forms of embedded transactions were observed, which I call reflexive trust, obligatory, and personage transactions. Reflexive trust transactions refer to life insurance purchases driven primarily by an extremely strong sense of trust, as a reaction to cultural schemas of intimate relationships without forethought. This kind of transaction took place only among strong ties (circles 1 and 2 in fig. 2). Obligatory transactions refer to life insurance purchases driven mainly by the norm of reciprocity, the etiquette of renqing. This kind of transaction took place mostly among strong ties but also among ties with midrange strength (circles $1-4$ in fig. 2). Personage transactions refer to life insurance purchases attributed to the agents' personal attraction and likability. This type of transaction took place among ties with midrange 
or weak strength (circles 4-6 in fig. 2). What is intriguing is that each of these embedded transactions was prevalent at a specific time, and each shift took place with a critical condition changed. Reflexive trust transactions were common at the very beginning when life insurance was an unknown commodity to the public. This form of transaction gave way to obligatory transactions when the commodity was somewhat known but unwanted. The popularity of obligatory transactions lasted for a while but was replaced by personage transactions when sales agents' commission sales system was made public. After the disclosure of the commission system, strong ties became a no-go zone for life insurance sales. In this section, I analyze how each form of embedded transaction is actualized by the relational properties that constitute tie strengths and why changes took place. This account will reveal the critical role of culture, meaning, and symbolic interaction in each of these embedded transactions and their dynamical shifts from one to another.

\section{Reflexive Trust Transactions among Strong Ties}

Buying insurance is an "unconsummated" transaction at the time of exchange. Trust is always the issue for this kind of intertemporal monetary transaction (Carruthers 2005). The mysterious terminology used in an insurance contract further perplexes and intimidates first-time buyers. Buying life insurance, thus, is itself a risk-taking activity. When AIA arrived in Shanghai in late 1992, it faced a population with no idea what life insurance was. This foreign insurer offered traditional risk management products and trained its Chinese sales agents to raise people's sense of risk and teach them the protective functions of life insurance. However, as premature death was a taboo topic for the Chinese, the agents found it extremely difficult to talk about it (Chan, in press). In fact, many agents themselves did not fully understand the concept of life insurance and the risk management logic of this commodity. They were repeatedly told by AIA's chief trainer, a Chinese British man who grew up in England, that life insurance was about familial love, family responsibility, security, respect, dignity, and benefiting society. They were taught to believe that selling life insurance was selling love and security, that selling life insurance was about helping people, not simply about making money off of them. In other words, insurers strove to sacralize this new commodity, so as to remove the new agents' "psychological barriers" to selling this commodity to their strong ties who had unwavering trust in them (Chan 2007). However, not all agents were receptive to the idea of selling a mysterious commodity to their relatives and close friends. Many of them soon left 
the industry, and some of them struggled to sell to strangers. ${ }^{9}$ Yet, a proportion of them came to believe that life insurance did serve a philanthropic function, and so they approached their intimate social circles to sell them this new commodity. These agents internalized AIA's indoctrination that they should bear the guilt if their close friends or relatives suffered from misfortunes without insurance coverage simply because they did not introduce this protection to them.

The agents who approached their relatives and close friends were generally successful because the problem of trust regarding life insurance as an unknown commodity was suspended by the cultural schemas of intimate relationships. As defined by DiMaggio (1997), schemas are both representations of knowledge and mechanisms for information processing. They simplify cognition and promote efficiency at the expense of absolute accuracy. The cultural schemas of "close friends and relatives" provide cognitive shortcuts to simplify the interpretations of the motives and behaviors of people in this category. They generate positive expectations in the face of uncertainty and facilitate decision making in unanticipated circumstances.

Among the clients interviewed, about one-fourth bought their first policy in or before 1995. More than $80 \%$ of these clients reported that they "had no idea what life insurance was" at that time. Then what made them purchase their first policy? Deng Lili (age 46), a client who bought a policy from AIA in 1995, recounted her purchase: ${ }^{10}$ "To be frank, I didn't know what I'd bought. Xiao (Junior) Zhen is my good friend. ${ }^{11}$ We've known each other for more than 10 years. I didn't know much about insurance. She called me one day and told me that she was working for AIA. I had heard of AIA. Some of its agents had come to our residence talking about insurance ... and I was not interested at all. But xiao Zhen is my close friend. She told me that insurance was good. If she thought that it was good for me, I thought it must not be bad" (interview, Shanghai, August 2002). The trust Deng had in the insurance agent was based on heuristic processing rather than calculation. Uzzi (1997) specifies trust in embedded ties as heuristic based, that is, "a predilection to assume the best when interpreting another's motives and actions" (p. 43). Building on this insight and going one step further, I propose that heuristic-based

\footnotetext{
${ }^{9}$ These early struggles were described to me in interviews with the senior sales agents who joined AIA in 1992-93.

${ }^{10}$ To protect the anonymity of the informants, I use pseudonyms throughout the text. I follow Chinese practice that puts the surname before the given name.

${ }^{11}$ When person A adds the word xiao or lao to the last name of person $\mathrm{B}$, it means that person A regards person B as quite a close friend. Xiao, which means "junior," is used when person B is younger than or about the same age as person A; lao, which means "senior," is used when person B is older than person A.
} 
trust, or the inclination to interpret the other party's motives in a positive light, is realized through a set of cultural schemas that define a close friendship or an intimate relationship. Examples of these schemas are "a close friend will not cheat me," "a close friend will not sell something bad to me," and "a close friend cares about my interests." Channeled by these cultural schemas, Deng interpreted the agent's motives in an altruistic flavor when the agent was her close friend. Through trusting the agent, Deng came to trust in the product the agent was selling.

Reflexive trust transactions largely took place when the general public in Shanghai was ignorant of what life insurance was, and there were no or very few regulations governing the market behaviors of the sellers or protecting the interests of the buyers. In this highly uncertain condition, the cultural schemas of intimate relationships facilitated life insurance transactions that required an extraordinarily high level of trust. Nonetheless, the critical condition for the cultural schemas of intimate relationships to be activated was that the buyers not be aware of the commission sales system or the fact that part of the premiums they paid directly went to the agents. As we will see in a later section, keeping the commission system covert was necessary for buyers to interpret the agents' motives as altruistic.

\section{Obligatory Transactions among Strong to Moderate Ties}

The period of relying on reflexive trust for transactions did not last long. Soon after the public learned that life insurance carried the inherent risk that the money they paid might not be returned if no misfortunes happened to them, they were much less interested in this new commodity. The "unknown commodity" turned out to be an "unwanted commodity." In response to this local resistance, AIA strove to educate the public about the risk management functions of life insurance. But the newly emerging domestic insurance company, Ping An, redefined life insurance as money management and offered products that served primarily a savings function to avoid the taboo topic of death. However, the interest rates offered on these savings products were not competitive enough to appeal to the general public. So, neither AIA products nor Ping An products were appealing. How could the agents sell them?

The answer is the etiquette of renqing. Etiquette embodies a set of customs and rules that define socially acceptable and appropriate behaviors. It sanctions behaviors via widely diffused norms, and such norms create culturally specific expectations on others (Zukin and DiMaggio 1990; Nee and Ingram 1998). Renqing, loosely translated as "interpersonal obligations," by definition involves a giving and a receiving party such that the receiving party owes the giving party an obligation. Thus, the 
enactment of renqing is always asymmetric. The etiquette of renqing commands that members of good relationships should enact asymmetric obligations to each other. It demands that members offer sympathies, affections, face, and favors to those who are in need for the sake of reproducing and strengthening the relationships.

Buying a life insurance policy in order to observe the etiquette of renqing was very popular in the mid-1990s. The local people described the life insurance market in this early phase as "a market of renqing baodan" to characterize the fact that most transactions were driven by interpersonal obligations, or renqing. Three different forms of obligatory transactions driven by three different manifestations of renqing can be identified, namely, sympathetic-affective, face-giving, and indebted transactions.

Sympathetic-affective transactions.-Zhao Anpei (age 38) and Wei Jinggang (age 43) had been coworkers in a state-owned factory, and they considered each other very close friends even after they left the factory. Zhao was a single mother with an 8-year-old daughter. Wei was sympathetic to her situation as a single mother and as the breadwinner of her family. Being a new agent, Zhao at first felt uneasy approaching her intimate social circles. However, when she failed to meet the sales quota during her probation period, she approached Wei and simply told him that she needed to meet a sales quota. Without hesitation, Wei bought a policy from her. "Xiao Zhao and I have been very good friends for more than twenty years. I always regard her as my younger sister. . . . I bought a policy from her as I wanted to help her. You know, it's tough to be a sales agent . . . [but] I actually didn't know what I bought. I don't really care about the product. I just wanted to help her" (interview, Shanghai, August 2000).

Social psychologists have long discussed how emotions matter in the reproduction of social relations (Lawler and Yoon 1998; Lawler 2001). The affective element in strong ties is often an influential force that motivates favor delivery (Krackhardt 1992). In the above example, Wei regarded Zhao as his fictive kin, and it was this affective bond that drove him to buy an insurance policy from her. Wei's primary motive was to help the agent rather than to gain benefit from the insurance policy. Transactions primarily driven by sympathies and affection occur only among strong ties (circles 1 and 2 in fig. 2).

Face-giving transactions.-Although the Chinese concept of "face" has multiple meanings in different contexts, Goffman (1967, pp. 5-12) has provided generalized definitions of "face" and "face giving" that are derived from Chinese usage. Accordingly, "face" can be defined as the socially approved and positively evaluated attributes a person claims for himself by the line others assume he has taken during a particular contact. "Face giving" refers to arranging a better line for a person or a group of persons 
than the person or the group might otherwise have been able to take. If someone "loses face," the person loses social standing in the opinion of known or knowable social circles (Hertz 2001). Mobilizing the norm of face giving was a very common practice among the Chinese sales agents. However, as rendering face and favor in Chinese relations is not random, but instead follows a concentric and hierarchical structure, asking for face and favor requires competent cultural knowledge and dramaturgical skills. The following example is illustrative of this point.

Cai Xiaojin (age 25) is a nephew of Hu Jiao (about age 45). Being a new agent of Ping An, Cai visited Hu three times in two months. During his visits, he never explicitly suggested to his uncle that he buy a policy. In his last visit, he skillfully used his mother as a resource to ask for face giving. "My mom is happy that I've taken up this new job [of insurance sales]. . . . She believes that being an agent is meaningful, because you are bringing something important to someone you care for." ${ }^{\prime 2}$

Because Cai's mother is an elder sister of $\mathrm{Hu}$, she customarily commands his respect. However, because $\mathrm{Cai}$ is younger than $\mathrm{Hu}$, he has relatively less authority to request face. To play it safe, Cai used his mother to ask for face. When he said that his mom viewed selling insurance as a meaningful and important mission, he was subtly asking his uncle to give face not only to him but to his mother. $\mathrm{Hu}$ had already bought a policy from AIA and did not feel that he needed another one from Ping An. Nevertheless, he bought a policy from Cai because, he said, "Cai is my nephew. It's hard to say 'no' to him. You know, he is my nephew. I need to give him and my sister a bit of face. I wouldn't have bought any if he weren't my nephew" (interview, Shanghai, October 2001). In return, Cai offered a discount on the premium of the policy. Hu continued: "When I gave him [Cai] the money, he said I only had to give him half of the amount. He said he would pay for the other half of the first month's premium. . . . He said, 'You are my uncle. I should give you a special offer.' I told him that he didn't have to do so. But he insisted" (October 2001). This exchange of favors - one party giving face and the other party giving a small amount of monetary or material return-is instrumental in maintaining and strengthening the preexisting relationship. I should note that the discount on the premium was offered not to induce the purchase since it was made after $\mathrm{Hu}$ already agreed to buy. Hu's purchase was based on face giving, a normative conformity enacting the interpersonal obligation that defines the significance of a relationship. Likewise, Cai's offer of a discount served to express the unique quality of the relationship. A refusal from either party to conform to these norms would

${ }^{12}$ This quotation is from an interview with Hu Jian (October 2001), who paraphrased what Cai Xiaojin said to him. 
not only elicit embarrassing or apologetic feelings (Elster 1989) but also demean the significance of the relationship.

The enforcing power of face is highest in those relationships in which both parties could end the relationship but have less flexibility and freedom to do so. Relatives belong to this category. Friends who share some common interests and social circles, and whose interests and reputations would be at stake if the friendships ended, are also more likely to give face to each other. Face-giving transactions take place in relationships that are defined more by an asymmetric obligation than a symmetric one (circles 2 and 3 in fig. 2). ${ }^{13}$

Indebted transactions. - In both sympathetic-affective and face-giving transactions, the buyers are the parties who deliver asymmetric obligations to the agents in the first place. Some agents then offered discounts or presented gifts in return. Another form of obligatory transaction begins with the agents' provision of favors to their prospects. After receiving the favors, the prospects feel indebted to the agents. In other words, the agents first perform asymmetric obligations to the prospects to earn obligatory credits. The credit slips (Coleman 1988) often induce purchase from the prospects as a way of repaying the favor to the agents.

Li Fei (mid-30s) and Yang Ji (mid-30s) were colleagues until Yang left to become an insurance agent for AIA. Li soon bought two insurance policies from Yang. When asked what made him buy life insurance, he said that "the agent xiao Yang is my ex-colleague. He's a very helpful and nice person. Once he did me a big favor by helping my son to get into the high school that we liked. . . . I always felt indebted to him. . . . This time he came to sell insurance. I didn't care much about insurance. But it's okay to buy some from him. . . . This is like a way of returning him a favor" (interview, Shanghai, April 2002). This case demonstrates that the primary driving force for the transaction was Li's sense of indebtedness to Yang. Offering help to former colleagues, schoolmates, friends, and existing clients in order to create a sense of indebtedness to induce purchase has been a common practice of Chinese sales agents. However, some agents are more successful than others in bringing forth indebted transactions. Those who behave as though they offer help without a sales agenda are more effective in orchestrating indebted feelings from the prospects. In the above case, Li attributed Yang's helpful behavior to being a "helpful and nice person" rather than to the intention of selling him insurance. Therefore, the dramaturgical gestures and performances of the sellers to a large extent affect the outcome. Indebted

\footnotetext{
${ }^{13}$ Face-giving transactions rarely occurred in the strongest ties (circle 1 in fig. 2) because the very intimate relationships, such as parent-child, spousal, and sibling relationships, are maintained and strengthened more through affective than face exchanges.
} 
transactions typically occur in midrange tie strength, in which asymmetric favors offered by one party are soon to be returned by the receiving party in a different kind (circles 3 and 4 in fig. 2).

\section{Strong Ties Became a No-Go Zone}

Obligatory transactions, which are primarily driven by relational bonds, were most prevalent in 1995-96, when virtually all life insurance products had little appeal. Between 1997 and 1999, transactions took place in all tie strengths, from very strong to arm's-length, as life insurance products became more appealing. Since mid-1996, there have been seven consecutive interest rate cuts in China. In order to capture the life insurance market, Ping An and other domestic insurers did not adjust their products' guaranteed interest rates accordingly, making their products competitive savings plans (Chan 2009). When the products were attractive, there was no need to rely only on the etiquette of renqing to sell, though selling to those in strong ties was still common. Toward the end of 1999, however, embedded transactions in relation to tie strengths took a new twist. Strong ties became a constraint on life insurance sales. When I was in the field, I observed that insurance agents often felt ambivalent about approaching their existing good friends and relatives. Selling to close intimates became undesirable and negatively labeled as "unprofessional." Instead, the agents made a great effort to build friendship or fictive kinship with "not-tooclose" friends, distant acquaintances, and referred prospects. Why did this shift occur toward the end of 1999?

Three contextual changes were observed at the time when insurance agents began to refrain from approaching close intimates for insurance sales. The first change supports Guthrie's argument that the rational-legal model has been gaining importance. The official regulatory body, the China Insurance Regulatory Commission (CIRC), was established in 1998. This authority formulated and enforced insurance law and regulations, overseeing insurance business operations, protecting the interests of policyholders, and maintaining order within the market. As the market became relatively regulated, the public's generalized trust in the insurance industry gradually increased. This led to a decrease in reliance on reflexive trust that is found only in intimate guanxi.

However, increasing institutionalization cannot fully explain the sudden shift of the target groups from strong to weak ties. Despite the increasing regulations on the market, life insurance and insurance sales agents did not enjoy a favorable public image. This constituted a second contextual factor that discouraged transactions in close personal relations. The idea that life insurance was a modern risk management mechanism was still not widely accepted after the establishment of the CIRC. In dealing with 
the public resistance, some insurance sales agents, especially those from the domestic insurance firms, presented life insurance as a money management device and exaggerated the benefits of their products. As a result, sales agents earned a pushy image and the life insurance companies acquired a money-grubber image. The negative public image and low social status of insurance agents deterred agents from approaching their close friends and relatives for fear of losing face.

The negative image of insurance agents was intensified by a third contextual factor: the disclosure of the commission sales system to the public. This disclosure, I argue, was the most critical factor that led to the sudden shift of where transactions took place. Making a living based on commissions, a concept introduced by AIA, was new to the local population. ${ }^{14}$ Knowing that the local people might not accept this concept, insurers and their agents tried to conceal their payment system. ${ }^{15}$ However, some agents offered discounts to their prospects and unintentionally leaked bits and pieces of information about the commission system. Such information was then circulated by word of mouth. However, people still did not know exactly how the commission system worked or the amount of commissions the agents received. Toward the end of the 1990s, more life insurers joined in the market and pushed the demand for sales agents. They dramatically exaggerated the income of insurance agents in recruitment advertisements in the most widely read local press in order to recruit aggressive and ambitious agents. They not only made transparent how the commission system worked but created rumors that many insurance agents had made a fortune. These advertisements changed people's perception of the motives of their close friends or relatives who sold them insurance.

It was the cultural schemas of intimate relationships that framed the prospects' interpretations of the agents' motives in a highly positive light. When the commission sales system was made known, another line of cultural schemas that defined commercial-oriented sales set in. Schemas such as "commercial sales are profit oriented," "commercial sales are designed to make money," and "commercial sales exaggerate the value of a product" are in conflict with the ethical-affective definition of intimate relationships. A person can be profit oriented, but she or he should not apply this orientation to good friends and relatives. Some of the clients who previously did not know about the commission system felt cheated.

\footnotetext{
${ }^{14}$ There were sales jobs in state-owned enterprises before the marketization of the economy, but salespersons received fixed salaries. If there were commissions, they were understood as extra "bonuses" on top of salaries.

${ }^{15}$ During my field research in 2000-2004, Ping An and China Life's agents were not given any printed information about the commission rates on the sales of different products, fearing that the agents might accidentally disclose such information to their clients.
} 
Ma Xiaojun (mid-40s) bought two policies from her good friend a few years ago. Now she felt that her friend had taken money out of her pocket: "When I bought these policies, I didn't know what they were. I trusted the agent. She's one of my very good friends. . . . I just bought what she recommended. . . . At that time, I didn't know that she actually took 40 percent of the premiums I paid into her own pocket. . . . I was a bit shocked, honestly. How should I put this . . . it's fine that she was selling insurance to make a living. But I don't feel good when she's making money off of me" (interview, Shanghai, August 2002). Ma bought the policy because of her reflexive trust in the agent. However, the disclosure of the commission system was like an "inopportune intrusion" that exposed the backstage of the agent's performance (Goffman 1959, p. 209). Since reflexive trust is grounded in the cultural schemas of intimate relationships, the exposure of the economic gains of one party in this relationship breaks the foundation of the trust (Molm et al. 2000). The disclosure of the commission system not only changed the prospects' perception and interpretation of the sales agents' motives but also changed the symbolic meanings of agents' behaviors and affected the feelings and self-image of the agents when they approached their close friends. When it became transparent that agents lived on commissions, the agents felt as though, in their words, they were "begging for money" when selling insurance to their close friends and relatives. Meanwhile, they worried that the commissions would become an issue that ruined their preexisting strong ties. Thus, the agents actively withdrew from approaching their intimate circles. The agents, under the pressure to sell, initially violated the cultural rules on which reflexive trust was based. However, such violations were not sustainable in the long run. ${ }^{16}$

Selling to close friends and relatives, nonetheless, is not entirely impossible. It is possible if the agents are willing to offer discounts with rates comparable to the commission rates they would receive. In this way, they are no longer selling for economic gains. Chang Pingkai, a young

\footnotetext{
${ }^{16}$ Thanks to a reviewer who insightfully pointed out that by selling to their intimate circles without revealing the economic gains behind the sale, the insurance agents indeed violated cultural expectations to exploit their strong ties. The reviewer interpreted this violation as an indicator of economic interests overriding the cultural rules of relational embeddedness, and that the cultural rules were not doing much work. I maintain that the binding force of the cultural rules was working; otherwise, the agents would not have had "psychological barriers" to selling to their strong ties initially; nor would they have avoided approaching their close ties once the commissions were made public. Some of their close friends and relatives would still be likely to observe (though reluctantly) the etiquette of renqing and buy a policy from them if the agents kept approaching them. The agents' active and instant withdrawal was driven less by economic calculation than by their concern about the meanings of their behaviors in the eyes of their strong ties.
} 
insurance agent of a domestic insurer, described how his relatives were demanding asymmetric exchanges from him: "[The recruitment advertisements] posted that insurance agents could earn one million in five years. This is a lie. . . . But my clients called me after they saw the ads. They said I had made a fortune. . . . Some of them, mostly my relatives, asked if they could get some rebates [huikou]. It was very embarrassing. Even if they didn't ask me for that, they knew that I got 40 percent of the premiums they paid. This made me feel embarrassed and uncomfortable" (interview, Shanghai, September 2000). The request for rebates by Chang's relatives is less about exploiting their guanxi with Chang and more about negotiating the meanings (Fine 1996) of their guanxi. When an agent sells a product to a close intimate, the agent's willingness to cut the price, and by how much, carries an evaluative statement on the relationship. The more the agent is willing to cut the price, the more it signifies the importance of the bond. Nonetheless, fulfilling the symbolic and expressive demand for asymmetric exchanges is economically costly to the agents. After all, the agents were living on commissions. Not to fulfill such a demand, however, would be socially and emotionally costly. When the agents are perceived as putting their economic interests over the relationship, it not only hurts the agents' relations with friends and relatives involved in the transaction but hurts the "face" of the agents and ruins their social reputation (Raub and Weesie 1990). Some agents reported that they felt so uncomfortable after selling to close friends and relatives that they used the commissions to buy gifts for these clients. Thus, the conflict between ethically-affectively defined close personal relationships and commercial-oriented sales, together with the expectation of asymmetric exchanges in these relationships, ultimately make circles 1 and 2 in figure 2 a problematic relational zone for life insurance sales.

Personage Transactions among Moderate to Weak Ties

Approaching moderately to loosely connected or referred social contacts became a more "respectable" or "professional" way of selling in the early 2000s. The moderately to loosely connected preexisting social ties (circles 4 and 5 in fig. 2) are best understood as laiwang (keeping in touch) circles in the Chinese concept. An agent of AIA explained why laiwang friends are better prospects than close friends or relatives: "I don't sell to my relatives or close friends. . . . Selling to former schoolmates and neighbors is better. Why? . . . They have a certain degree of trust in me. But they are not my close friends. When I approach them for business, I can interact with them in a business-like way" (interview, Shanghai, January 2002). Laiwang circles are better target groups for insurance sales for both their structural and relational qualities. The structural embeddedness literature 
has provided us with insights on why moderate to weak ties are structurally better for various economic exchanges, so I will not repeat them here. What I would like to emphasize is the relational advantages enjoyed by these ties. While intimate relations are defined more by affection and obligation, laiwang relations are defined by courtesy and immediate reciprocity. They are governed by a mix of ethical-affective and instrumentalmonetary principles and constituted by a relatively balanced composition of trust, affection, obligation, and calculation. A laiwang relationship bears a higher degree of freedom to let economic interests intermingle with personal interactions without violating the definition of the relationship. Calculating one's economic interests in an exchange with a laiwang friend is more legitimate than doing so with a close friend. At the same time, both parties in a laiwang relationship have some sense of trust in each other. For the agents, they have some space to express their self-interest, and it requires less effort to deal with the problem of trust. Moreover, the prospects are less likely to expect a discount in price in a laiwang relationship that contains relatively balanced obligations. For the prospects, they are under a lesser degree of obligation to buy from the agents. They feel more comfortable asking questions and expressing concerns about the products. Thus, this kind of relation provides more space for buyers and sellers to move in and out of transactions and to test each other's credibility in order to protect their economic interests.

However, unlike the prospects in intimate relations, the prospects in laiwang relations are under less obligatory pressure to buy from a particular agent. They first have to feel a certain sense of need for life insurance. A sales agent first has to frame life insurance as money management so as to make it more acceptable to the local people (Chan 2009). Next, the agent has to compete with other sales agents for closing a deal. What makes a prospect buy from one agent over another is often attributed to the personal qualities of the agents and how much the prospect likes the agent, which can be conceived of as a "personage transaction." This form of transaction is neither purely economic nor primarily relational but a mix of both. The purchase is based on a certain sense of need for insurance but is noncommittal, and from whom the prospects purchase depends on which agents they personally like. In China, the most effective way of being a likable person is what the agents call "affective investment" (ganqing touzi). The most common cultural resources that the insurance agents mobilized are the etiquette of renqing and the bonds of kinship. Their strategies are to actively offer asymmetric favors to induce indebtedness and to relate to the prospects as though they were fictive kin. The following two examples are illustrative of these practices.

A filial daughter-in-law.-Chang Qing (age 27), an agent of Ping An, was relatively new but was making good progress in her sales perfor- 
American Journal of Sociology

mance. The following episode reveals how she strengthened her relationship with a client for referrals:

On the birthday of one of her clients, Chang took her 3-year-old son with her and taught him a Chinese blessing, "wishing you health and to live a hundred years," to say to her client, Wang Chun. She bought a scarf that cost 10 yuan [US\$1.20] as a birthday gift and arrived at Wang's residence early in the morning. Wang, aged over 50 and suffering from a deformed leg, was very moved when she saw the agent and the little boy. The boy was barely able to say "wishing you health." Wang bent her waist to reach the boy's face to show affection. . . . She was very touched by what Chang had been doing. Chang had visited her just two weeks before on Women's Day and gave her a carnation. Wang felt much indebted to her kindness. She went to her bedroom for a few minutes and came out with tears in her eyes. She walked over to the boy and put a note of 100 yuan [US\$12] into his pocket. . . . During their chat, Wang told Chang that the last wish in her life was finding a wife for her 25-year-old son. She said if she could have a daughter-in-law like Chang, she could be at ease for the rest of her life. ${ }^{17}$

Wang, in an interview with this author, compared her feelings about Chang to her feelings about other agents who had approached her. She was approached by altogether four different agents, who all knocked on her door without appointments. She was impressed by two of them: an agent from Aetna and Chang. When they first met with her, each chatted with her for almost an hour without even mentioning insurance. She liked their nonpushing and caring attitude. Chang finally won her over, Wang recalled, because she sent her a greeting card with warm wishes and phoned her during the Lunar New Year. The agent from Aetna also called her once to show concern, but she felt that Chang was more sincere and cared about her more. She felt that Chang could be a real friend (interview, Shanghai, April 2002). To orchestrate an indebted feeling from Wang, Chang did treat her as though she was her kin. She bought her gifts and visited her on festivals. She mobilized her son to participate in the dramaturgical stage. By getting her little boy involved, Chang effectively elicited not only an indebted feeling but also a familial sentiment from Wang, who then wished Chang to be her daughter-in-law. With this fictive kin bond, Wang not only referred her relatives and neighbors to Chang but went one step further to help convince them of the importance of insurance.

A naive sister.-Zhang Ying (age 24) was one of the top sales agents of Allianz-Dazhong. The selling strategy Zhang often used was to present

${ }^{17}$ The agent, Chang, shared with other agents her experience in establishing guanxi with clients and prospects in a morning assembly in an agency office of Ping An in April 2002. 
herself as a naive girl in front of the prospects to establish sibling-like relationships with them. The following extract of my field notes describes how Zhang successfully sold a "big policy" to an existing client.

Zhang got to know Hang through her father who once had a business deal with him. For more than a year Zhang was trying to sell a bigger policy to Hang. She was not able to close the sale because Hang's wife, whom Zhang called sister Li Yun, was reluctant to buy from her. . . . When she learned that $\mathrm{Li}$ was pregnant, she bought a book called "How to Raise Your Lovely Baby" and sent it to her along with a greeting card. . . . After the baby was born, Zhang bought a can of formula and a bunch of lilies as gifts for $\mathrm{Li}$ and the baby. She also brought a "big policy" proposal with her and presented it to the couple. . . . Sometimes Zhang simply put on a pitiful face when her client became too critical of the proposal. . . .

Before she left, Zhang deliberately walked over to the couple's wedding picture. She exclaimed in a naive tone, "Sister Li Yun, you are so beautiful! . . ." [However], two days later, Zhang received a call from the headquarters, saying that Li Yun wanted to terminate her husband's existing policy in Allianz-Dazhong. This made Zhang anxious and worried. She called Hang, who then invited her over to his workplace the following day. . . . She sat down and looked upset. Instead of talking about insurance, she talked about her feelings: "Brother Ganzhi, is it true that sister Li Yun doesn't like me? Tell me the truth, please. . . . Did I do something wrong? I felt hurt when I got the phone call from the headquarters that sister $\mathrm{Li}$ Yun wanted to terminate the policy." Hang comforted her, saying that he was pleased with the proposal she presented. . . He convinced his wife to agree on a new purchase from Zhang. The annual premium was over 30,000 yuan $[\mathrm{US} \$ 3,615] .^{18}$

Zhang, who had a preexisting weak tie with Hang, had been making a great effort to transform their relationship to a fictive kin tie by sending gifts, acting as a caring and yet naive little sister, and talking about personal feelings. Presenting herself as a caring person to his wife and as a naive little sister to Hang was quite effective in soliciting Hang's sympathetic feelings for her. These feelings, together with his favoring the policy Zhang presented, prompted him to convince his wife about the purchase.

Mobilizing the etiquette of renqing together with the bonds of kinship is a powerful way of making guanxi with clients and prospects in the Chinese context. The Chinese sales agents tactfully capitalize on the norm of reciprocity by actively presenting gifts and rendering favors to make their clients and prospects feel indebted and obligated to repay their favors. "The Chinese are afraid of being cared for by someone. When some-

${ }^{18}$ The agent, Zhang, shared her successful story with other agents in a small group meeting in an agency office of Allianz-Dazhong in May 2002. The annual premium, US $\$ 3,615$, was 10 times more than the majority of the policies sold in Shanghai. 
one cares for them persistently, they feel indebted to that person," a Ping An agent said. The importance of repaying a favor, which is rooted in the Confucian teachings of how to maintain social order, is stipulated in the common aphorism lishang wanglai (gifts coming and returning). Furthermore, the etiquette of renqing encourages returning more than what you have received. It is expressed unmistakably in this Chinese aphorism: nijingwoyichi, wojingniyizhang (you respect me for a foot, I respect you for 10 feet). ${ }^{19}$ As a case in point, Chang's client offered 100 yuan to the little boy when Chang's gifts, including both the scarf and the carnation, cost much less. When the principle of repaying more than the amount received is applied to the exchanges between sales agents and prospects or clients, the repayment of favors from prospects or clients, more often than not, is to buy a policy or refer someone to the agents.

\section{ENCAPSULATION AND GENERALIZATION}

The ethnographic data above, which are encapsulated in table 1, illustrate different forms of embedded transactions in different tie strengths under different conditions. Reflexive trust and obligatory transactions occurred mostly among strong ties when the new commodity was either unknown or unwanted by the public majority, market regulations had not yet been established to protect the buyers, and the economic interests of the sellers were covert. When the prospects had no or very little knowledge of the new commodity, the cultural schemas of intimate relationships were activated to suspend the problem of trust when sellers were close friends or relatives. When the prospects came to know more about the new commodity but still did not have a sense of need for it, affection and the norm of reciprocity, or the etiquette of renqing, constituted by endless cycles of asymmetric obligations between members were mobilized to achieve the sale. In both reflexive trust and obligatory transactions, sellers hid, downplayed, or moderated their economic interests and buyers engaged in the purchase as reciprocal exchanges. When market regulations began to emerge to protect life insurance clients, relying on the relational properties that are found only in strong ties became less necessary. However, what made strong ties a constraint on life insurance sales was the exposure of the commission sales system to the public. Sales agents avoided selling to strong ties precisely to preserve the significance of those ties. When concentrating on selling to those moderately to loosely connected social

${ }^{19}$ Zhang is a unit of length used by the Chinese for centuries until Communist China. Yizhang refers to one zhang, which equals 3.33 meters. As one meter is approximately three feet, I use 10 feet to represent one zhang, even though this representation may not be perfect. 
Life Insurance Transactions in China

TABLE 1

Summary of Different Forms of Socially Embedded Transactions

\begin{tabular}{|c|c|c|c|}
\hline & \multicolumn{3}{|c|}{ EmbEDdED TRANSACTION } \\
\hline & Reflexive Trust & Obligatory & Personage \\
\hline Where & Very strong ties & $\begin{array}{l}\text { Very strong to mid- } \\
\text { range ties }\end{array}$ & Midrange to weak ties \\
\hline When & $\begin{array}{l}\text { 1. Unknown products } \\
\text { 2. Lack of market } \\
\text { regulations } \\
\text { 3. Covert profit making } \\
\text { of sellers }\end{array}$ & $\begin{array}{l}\text { 1. Unwanted products } \\
\text { 2. Lack of market } \\
\text { regulations } \\
\text { 3. Covert profit making } \\
\text { of sellers }\end{array}$ & $\begin{array}{l}\text { 1. Somewhat wanted } \\
\text { products but } \\
\text { noncommittal } \\
\text { 2. Some market } \\
\text { regulations } \\
\text { 3. Overt profit making } \\
\text { of sellers }\end{array}$ \\
\hline How & $\begin{array}{l}\text { Mobilizing the cultural } \\
\text { schemas of intimate } \\
\text { relationships by hid- } \\
\text { ing or moderating the } \\
\text { economic interests }\end{array}$ & $\begin{array}{l}\text { Mobilizing affection } \\
\text { and the norm of reci- } \\
\text { procity by hiding, } \\
\text { downplaying, or } \\
\text { moderating the eco- } \\
\text { nomic interests }\end{array}$ & $\begin{array}{l}\text { Making guanxi to boost } \\
\text { trust, affection, and } \\
\text { asymmetric } \\
\text { obligation }\end{array}$ \\
\hline
\end{tabular}

circles, they engaged themselves in a variety of dramaturgical interactions with the prospects to inflate elements of trust, affection, and asymmetric obligation that were relatively weak in their preexisting loose ties with the prospects. They strove to build closer guanxi with the prospects in order to compete against each other.

This article argues that strong ties are in general a less desirable relational category for direct economic transactions. The ethical-affective principle that defines intimate relationships and the high intensity of trust, affection, and asymmetric obligation stands in conflict with economic transactions that are defined by economic interests and calculations. Ties with midrange to weak strength are the better category of social relations for economic exchanges because of their relational complementarity, namely, a relatively balanced composition of trust, affection, obligation, and calculation. The trust and affective components lower the transaction costs, and the symmetric obligation and calculation components allow self-

interest-driven economic behaviors. Only under certain extreme institutional or contingency conditions do economic transactions occur in strong ties. In any case, transactions do not occur automatically even under the favorable conditions. Dramaturgical interactions between sellers and buyers are no less universal and important an integral part of social embeddedness. It is through interactions that the relational qualities of a dyad 
American Journal of Sociology

are not entirely fixed by their preexisting structural positions in a network, and emergent structures (Ibarra 1992) are produced.

To what extent can the above analysis be generalized beyond the case of life insurance in China? As I specified at the beginning, life insurance belongs to a negotiated direct exchange that potentially carries a conflict of interests between the parties involved (Molm, Collett, and Schaefer 2007). Life insurance transactions represent economic activities that involve negotiations over prices and terms, and one party's excessive gains are another party's losses. Most retailing, direct selling, trading, subcontracting, and employment are negotiated economic exchanges. Strong ties as a constraint on direct transactions can be generalized to these economic activities across nations and cultures. A number of studies support this claim. Jeffery's (2001) ethnographic research on direct selling in China notices that reliance on the close guanxi networks to build pyramids for layered extraction of commissions was subject to general public distrust and state condemnation. Moving beyond China, Velez-Ibanez's (1983) study of banking practices in Mexican communities reveals that making profits among members of close ties is devalued because personalism, which is highly valued in Mexican culture, is defined by trust and obligation. In the United States, DiMaggio and Louch (1998) find that the majority of the respondents in the 1996 General Social Survey agreed that negotiating price was awkward and socially uneasy when trading with friends. Aldrich and Sakano's (1998) cross-national comparison of personal business networks in Japan, the United States, Italy, Ireland, and Sweden reports that only a small group of business associates in small to medium-size firms are friends, and almost none are family members in all the nations studied. All these case studies suggest that strong ties are a less than ideal category of social relations for market-oriented economic exchanges.

This generalization, however, has it limits. First, it does not apply to economic activities in which the interests of the parties involved align with each other. Strong ties are likely to be the preferred type of relations for business partnerships (Kao 1996) and joint investments (Lee 1990; Numazaki 1996). They are also preferred for non-profit-oriented economic activities. The rotating credit association is an example of this kind (Biggart 2001). Second, the argument does not apply to economies that are either closed or too small to have ties other than the strong category for negotiated direct economic exchanges. Some immigrant or enclave economies belong to this category (Portes, Castells, and Benton 1989). Finally, as collateralized social relations serve as presumptive guarantees for managing risky transactions (Biggart and Castanias 2001), strong ties are likely to be where direct economic exchanges take place in a highly uncertain environment. If the products or services in exchange are highly complex 
or if formal institutional protections are absent, trading partners are likely to rely more on reflexive trust that is found only in strong ties (Guseva 2008).

The analytic frame developed for understanding the shift of life insurance transactions from strong to weak ties in China can be applied to other social and cultural contexts for projecting what kinds of embedded transactions are likely to take place in what ranges of tie strengths. The two postulates-one that strong ties are defined by an ethical-affective principle and constituted by trust, affection, and asymmetric obligation and one that weak ties are defined by an instrumental-monetary principle and constituted by symmetric obligation and calculation-can be generalized to non-Asian contexts. So can the proposal that dramaturgical performances, especially on the part of the parties that seek exchanges, are an integral part of the socially embedded transaction. Nevertheless, the level of intensity of each relational property in different tie strengths should be modified according to a specific time and locale when the analytic frame is applied. For instance, in a highly institutionalized economy with a high level of legal protection that generates a higher level of generalized trust, the level of trust in columns 5 and 6 of figure 1 will be higher than that in the hypothetical model. In a Christian community in which universal love is often invoked, the level of affection in weak ties will be higher. In a highly individualistic society, asymmetric obligation even in strong ties may be less intense than that in the hypothetical model. Furthermore, as what counts as appropriate reciprocity varies across time and space, dramaturgical interactions among actors vary from time to time and from place to place. What remains universal is the direction of intensity of various relational properties from the strongest to the weakest ties and the need for strategic interactions in all tie strengths.

There are two aspects of the above analysis that might be distinctively Chinese (or Asian). First, obligatory transactions might be more robust in Chinese or Asian societies in which harmony is emphasized and hierarchical relational order is a central social organizing principle (Hamilton 1996). As the norm of reciprocity that is manifested by renqing is "pervasive and dominant" in Chinese societies (Lin 2001), the enforcing power of asymmetric obligation in economic exchanges among close intimates is likely to be more profound in Chinese societies. This feature may also apply to some other Asian economies. For instance, the role of obligation in enforcing market behaviors is found more salient in the Japanese economy than in the Anglo-Saxon economies (Dore 1983; Lincoln, Gerlach, and Takahashi 1992). However, the stronger enforcing power of the role of obligation in the Chinese and Japanese economies does not negate its important role in other economies (Coleman 1988; Uzzi and Lancaster 2003, 2004). Second, as kinship and native place collegiality 
American Journal of Sociology

in Chinese guanxi render more trust and asymmetric obligation among members, the strategic interactions such as fictive kin are likely to be found more salient in China than in other places. Interacting with prospects as fictive kin is unlikely to be found in market economies in which universalism and individualism are the norm. For instance, in opposition to the Chinese insurance agents who extensively mobilized the norm of reciprocity to act as fictive kin, Leidner (1993) finds that the social convention of reciprocity is least employed by American insurance agents to induce conformity. Instead, they use jokes to break the ice to create a socially relaxing atmosphere for the subsequent economic negotiations. Therefore, it is a universal demand on the parties seeking transactions to enact dramaturgical performances in order to be likable (Oakes 1990; Leidner 1993), but how to be likable is culturally and temporally specific.

\section{CONCLUSION: CULTURE IN SOCIAL EMBEDDEDNESS}

As DiMaggio (1992) points out, network analysis can never be purely structural because the formal modeling of social relations is, in fact, based on assumptions about cultural and subjective aspects of action. In his words, when culture is "tossed out the front door, it returns through the back" (p. 121). This article tackles at the front door the impacts of cultural and subjective aspects of social relations on economic exchanges. It incorporates cultural sociology and symbolic interactionism into social embeddedness without posing culture and network in opposition to one other. Despite Granovetter's emphasis on trust and norms in organizing economic activities, he, unfortunately, conceives the mechanism of cultural rules in shaping human action as automatic, less reasonable responses to situations (1985, p. 506). His worry about conceiving economic action as a "cultural dupe" leaves the mechanism of culture in social network undertheorized. I argue that emphasizing the role of culture does not have to compromise the agency of the actors. The case of life insurance transactions in China demonstrates that culture is constitutive of social embeddedness in many different manifestations, from cultural schemas to normative rules, meanings, and a practical tool kit (Swidler 1986). Culture manifests both as cultural rules that define, prescribe, and organize interactions among members of different tie strengths according to their structural positions and as repertoires that provide symbols and practical skills for individual actors to creatively and effectively manipulate the interactions for their interests. The socially embedded transactions presented in this article are culturally constituted, but they are neither random nor automatic. Let me elaborate this point.

The extent to which business rationales and activities are morally le- 
gitimate in a preexisting personal relationship is subject to the primary principle that defines the category of relation the particular relationship belongs to. The defining principle is composed of cognitive and normative cultural rules that specify how the actors in a specific category of relation should interact to reproduce the relationship. The enforcing power of cultural rules is exercised through meanings. Meanings distinguish the interactions that follow the rules from those that violate them. Existing network analysis often takes expectations and obligations in embedded ties as given. But, as Powell and Smith-Doerr (1994) question, what kinds of expectations are set about how an individual should reciprocate in strong and weak ties? This article suggests that there is a pattern of expectations in relation to tie strengths, and such a pattern can be explained by cultural rules. In the Chinese case, for example, giving face to personal relationships that are closely to moderately connected is a cultural rule. Buying life insurance in order to give face expresses the significance of a particular relationship. Refusing to do so debases the meanings of the relationship. Likewise, it is against the cultural rules that render meanings to strong ties if one acts primarily on her or his selfinterest in an exchange. This explains why selling insurance to close ties in order to gain commissions was socially disapproved of. These cultural rules generate a pattern of expectations as to what kinds of tie strengths should deliver what kinds of obligations. As such, cultural rules, through the enforcing power of meanings, mold the pattern of the relation between tie strengths and forms of economic transactions.

While economic actors are bounded by their preexisting structural positions and the associated cultural rules, they definitely have the capacity to appropriate, reproduce, and innovate upon received cultural categories and situations of action in accordance with their personal interests (Emirbayer and Goodwin 1994; Mizrachi, Drori, and Anspach 2007). A crucial implication of integrating symbolic interactionism into network analysis is its capacity to transcend a static model and to display the dynamical nature of social embeddedness. DiMaggio (1992) comments that the structural models of embeddedness treat network membership and the access of each member to relations with others as fixed. The Chinese life insurance transactions compellingly demonstrate that even in a hierarchical network structure as solidified as the one of Chinese social relations, dramaturgical performances and interactions, if enacted properly, are capable of modifying individual actors' access to relations with others in a network. This is where the use of a cultural tool kit as an exercise of human agency comes to play. Although different types of preexisting relations carry different configurations of enabling and constraining elements pertaining to economic exchanges, skillful dramaturgical performances can either overcome the constraining elements by taking full 
American Journal of Sociology

advantage of the enabling ones or to some extent modify one's structural position to facilitate transactions. For instance, in intimate and close circles in which self-interested economic gains are illegitimate, the agents downplay and moderate their economic gains from the transactions so as to channel the prospects to interact with them according to the ethicalaffective principle. In distant circles in which the level of trust and affection is low and the element of calculation is high, the agents endeavor to make guanxi with the prospects by acting as though they were close friends or fictive kin to manufacture trust, affection, and indebtedness from the prospects. If successful, they move their structural positions closer to the Ego.

Whether the agents overcome the constraints or modify their structural positions, they draw on their local knowledge, which is part of their cultural tool kit, for guidance. For instance, agents Chang and Zhang both chose to interact with their clients as fictive kin. Their choices were informed, though not determined, by local knowledge that kinship bonds carried a high intensity of the elements they intended to cultivate. To successfully generate the kinds of trust, emotions, and obligatory credits as they intended to, they needed to choose what kinds of fictive kin roles they should perform and how to perform them effectively. Chang and Zhang chose different fictive kin roles to orchestrate different obligatory credits. The former acted as a filial daughter-in-law to induce a deep feeling of indebtedness from her client; the latter acted as a naive sister to earn her client's sympathy. Their different strategic choices illustrate that what kind of obligatory credits their clients hold depends on what the agents do and how their favors are received and interpreted. In other words, it depends on how the agents mobilize and organize the symbols of reciprocity and how the prospects and clients read these symbols. Therefore, while their structural positions and the preexisting relational properties stipulate that they need to interact with their sales targets in a certain way in order to succeed, there is no single formula for doing so. The actual interactions are subject to the actors' creativity and mobilization of local knowledge, interpersonal skills, and cultural symbols in response to the binding forces of structures, cultural rules, and situations. By conceiving culture as both cultural rules and repertoires, this article casts light on the constitutive force of meaning and agency in socially embedded economic exchanges.

Nevertheless, I should point out some limitations of this study and what has been left out. First, it focuses only on the moments when transactions take place without considering the long-term success of such transactions. It does not take into account the lapses of the insurance policies sold through different forms of embeddedness. Some scant data from my field research suggest that clients who bought their policies through re- 
flexive trust complained about the policies the most. This makes sense since these clients bought the policies without knowing what they were. I suspect that policies sold through reflexive trust have the highest lapse rate and those through personage transactions have the lowest. If so, it will further strengthen the argument that transactions among strong ties are less than ideal.

Second, this study centers on dyadic direct transactions without investigating mediated transactions. ${ }^{20}$ How do different tie strengths function differently in mediated transactions? Bian's (1997) study on job searches suggests that strong ties serve as a better bridge than weak ties in China. I suspect that this may hold for other types of mediated economic activities, including negotiated exchanges. For instance, if an intermediary has strong ties with both a sales agent and a prospect, the prospect is likely to trust the agent and to feel obligated to buy from the agent. To connect relational properties to the structure of tie strengths, it will be useful to study various combinations of mediated ties in terms of tie strengths. How would a two-strong-link triadic connection differ from a one-strong-link connection for business deals in China? How would the outcome be different if the one strong link were between an intermediary and a seller versus one between an intermediary and a prospect? The analytic frame that connects various relational properties to tie strengths is useful for hypothesizing the possible outcomes that go beyond dyadic transactions, especially with respect to the roles of trust and both asymmetric and symmetric obligations.

Finally, while different categories of Chinese social relations are presented, this study has little to say about how different categories of social relations, other than tie strengths, affect transactions. How do kinship and friendship differ in reflexive trust and obligatory transactions? How does trading with personal friends, even the loosely connected ones, differ from trading with long-term business friends? Most extant literature on embeddedness focuses on long-term business relationships. But, given that the history of a social relationship matters (Granovetter 1990), it is likely that different types of relations within a tie strength affect economic transactions differently. At least in Chinese societies, strong ties that started off as friends carry different meanings than strong ties that started off as business relationships. While it may be a problem to engage in direct economic transactions with the former type of strong ties, it may be an asset to do it with the latter type. All these questions and concerns await future research that put the content of social relations at the center of inquiry.

${ }^{20}$ For a concise discussion of linking dyadic exchanges to macro structures and networks, see Emerson (1976). 


\section{APPENDIX}

TABLE A1

Summary of Socioeconomic Profiles of the Interviewees in Shanghai

\begin{tabular}{|c|c|c|}
\hline & \multicolumn{2}{|c|}{ INSURANCE PRACTITIONERS } \\
\hline & Sales Agents & $\begin{array}{c}\text { Managerial } \\
\text { Staff }\end{array}$ \\
\hline \multicolumn{3}{|l|}{ Gender: } \\
\hline Male & 52 & 33 \\
\hline 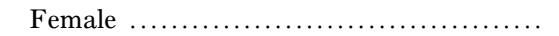 & 47 & 11 \\
\hline \multicolumn{3}{|l|}{ Age: } \\
\hline $20-29$. & 19 & 4 \\
\hline $30-39$. & 46 & 19 \\
\hline ......... & 24 & 19 \\
\hline 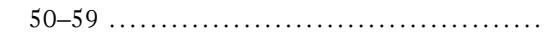 & 10 & 2 \\
\hline \multicolumn{3}{|l|}{ Seniority:* } \\
\hline Senior & 52 & NA \\
\hline Junior .... & 47 & NA \\
\hline \multicolumn{3}{|l|}{ Division: } \\
\hline General management $\ldots \ldots \ldots \ldots \ldots \ldots \ldots \ldots$ & NA & 8 \\
\hline Marketing and agency management ....... & NA & 18 \\
\hline Training $. . . \ldots \ldots \ldots . . . .$. & NA & 7 \\
\hline Product development & NA & 8 \\
\hline \multirow[t]{3}{*}{ Public relations $\ldots \ldots \ldots \ldots \ldots \ldots \ldots \ldots \ldots \ldots \ldots \ldots \ldots$} & NA & 3 \\
\hline & \multicolumn{2}{|c|}{ Clients and Prospects } \\
\hline & Clients & Prospects \\
\hline \multicolumn{3}{|l|}{ Gender: } \\
\hline Male & 46 & 16 \\
\hline Female & 50 & 19 \\
\hline \multicolumn{3}{|l|}{ Age: } \\
\hline $20-29$. & 20 & 8 \\
\hline 30-39 & 37 & 16 \\
\hline (1, & 28 & 6 \\
\hline (n..., & 10 & 5 \\
\hline 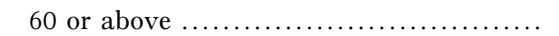 & 4 & $\ldots$ \\
\hline \multicolumn{3}{|l|}{ Annual income (yuan): } \\
\hline$<18,000 \ldots \ldots \ldots \ldots$ & 18 & 9 \\
\hline 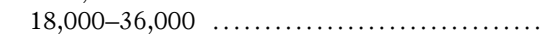 & 28 & 12 \\
\hline $36,000-84,000 \ldots \ldots$ & 26 & 10 \\
\hline $84,000-120,000 \ldots \ldots$. & 14 & 3 \\
\hline 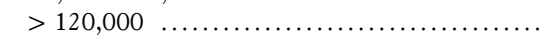 & 10 & 1 \\
\hline \multicolumn{3}{|l|}{ Occupation: } \\
\hline Blue-collar & 10 & 13 \\
\hline Lower-level white-collar ................. & 40 & 10 \\
\hline Upper-level white-collar $\ldots \ldots \ldots \ldots \ldots \ldots$ & 34 & 9 \\
\hline Self-employed/owners $\ldots \ldots \ldots \ldots \ldots$ & 12 & 3 \\
\hline
\end{tabular}


Life Insurance Transactions in China

\section{REFERENCES}

Aldrich, Howard, and Tomoaki Sakano. 1998. "Unbroken Ties: Comparing Personal Business Networks Cross-Nationally." Pp. 32-52 in Networks, Markets, and the Pacific Rim: Studies in Strategy, edited by Mark Fruin. New York: Oxford University Press.

$\rightarrow$ Baker, Wayne. 1990. "Market Networks and Corporate Behavior." American Journal of Sociology 96:589-625.

$\rightarrow$ Bian, Yanjie. 1994. "Guanxi and the Allocation of Jobs in Urban China." China Quarterly 140:971-99.

$\rightarrow \longrightarrow$. 1997. "Bringing Strong Ties Back In: Indirect Ties, Network Bridges, and Job Searches in China." American Sociological Review 62:366-85.

2002. "Institutional Holes and Job Mobility Processes: Guanxi Mechanisms in China's Emergent Labor Markets.” Pp. 117-36 in Social Connections in China: Institutions, Culture, and the Changing Nature of Guanxi, edited by Thomas Gold, Doug Guthrie, and David Wank. New York: Cambridge University Press.

$\rightarrow$ Bian, Yanjie, and Soon Ang. 1997. "Guanxi Networks and Job Mobility in China and Singapore." Social Forces 75:981-1006.

Biggart, Nicole. 1989. Charismatic Capitalism: Direct Selling Organizations in America. Chicago: University of Chicago Press.

2001. "Banking on Each Other: The Situational Logic of Rotating Savings and Credit Associations." Advances in Qualitative Organization Research 3:129-53.

$\rightarrow$ Biggart, Nicole, and Thomas Beamish. 2003. "The Economic Sociology of Conventions: Habit, Custom, Practice, and Routine in Market Order." Annual Review of Sociology 29:443-64.

$\rightarrow$ Biggart, Nicole, and Richard Castanias. 2001. "Collateralized Social Relations: The Social in Economic Calculation." American Journal of Economics and Sociology 60: 471-500.

Blau, Peter. 1964. Exchange and Power in Social Life. New York: Wiley.

$\rightarrow$ Bonacich, Philip. 1987. "Power and Centrality: A Family of Measures." American Journal of Sociology 92:1170-82.

Brinton, Mary, and Victor Nee, eds. 1998. The New Institutionalism in Sociology. New York: Russell Sage Foundation.

Burt, Ronald. 1986. "Comment." Pp. 105-7 in Approaches to Social Theory, edited by Siegwart Lindenberg, James Coleman, and Stefan Nowak. New York: Sage.

- 1992. Structural Holes: The Social Structure of Competition. Cambridge, Mass.: Harvard University Press.

Carruthers, Bruce. 2005. "The Sociology of Money and Credit." Pp. 355-78 in Handbook of Economic Sociology, 2d ed., edited by Neil Smelser and Richard Swedberg. Princeton, N.J.: Princeton University Press.

Chan, Cheris Shun-ching. 2007. "Honing the Desired Attitude: Ideological Work on Insurance Sales Agents." Pp. 229-46 in Working in China: Ethnographies of Labor and Workplace Transformation, edited by Ching Kwan Lee. London: Routledge.

$\rightarrow$. 2009. "How to Create a Market in the Presence of Cultural Resistance: The Case of Life Insurance in China." Theory and Society 38:271-305.

- In press. Marketing Death: Culture and the Making of a Life Insurance Market in China. New York: Oxford University Press.

Coleman, James. 1988. "Social Capital in the Creation of Human Capital." American Journal of Sociology 94 (suppl.): S95-S120.

$\rightarrow$ Davis, Gerald, and Henrich Greve. 1997. "Corporate Elite Networks and Governance Changes in the 1980s." American Journal of Sociology 103:1-37.

DiMaggio, Paul. 1992. "Nadel's Paradox Revisited: Relational and Cultural Aspects of Organizational Structure.” Pp. 118-42 in Networks and Organizations: Structure, 
American Journal of Sociology

Form, and Action, edited by Nitin Nohria and Robert Eccles. Boston: Harvard Business School Press.

$\rightarrow \longrightarrow$. 1997. "Culture and Cognition." Annual Review of Sociology 23:263-87.

$\rightarrow$ DiMaggio, Paul, and Hugh Louch. 1998. "Socially Embedded Consumer Transactions: For What Kinds of Purchases Do People Most Often Use Networks?” American Sociological Review 63:619-37.

$\rightarrow$ Dore, Ronald. 1983. "Goodwill and the Spirit of Market Capitalism." British Journal of Sociology 34 (4): 459-82.

$\rightarrow$ Elster, Jon. 1989. "Social Norms and Economic Theory." Journal of Economic Perspectives 3:99-117.

$\rightarrow$ Emerson, Richard. 1976. "Social Exchange Theory." Annual Review of Sociology 2: $335-62$.

. 1981. "Social Exchange Theory." Pp. 30-65 in Social Psychology: Sociological Perspectives, edited by Morris Rosenberg and Ralph Turner. New York: Basic Books.

$\rightarrow$ Emirbayer, Mustafa, and Jeff Goodwin. 1994. "Network Analysis, Culture, and the Problem of Agency." American Journal of Sociology 99:1411-54.

$\rightarrow$ Espeland, Wendy Nelson, and Mitchell Stevens. 1998. "Commensuration as a Social Process." Annual Review of Sociology 24:313-43.

Fei, Xiaotong. (1948) 1992. From the Soil: The Foundations of Chinese Society. Translated by Gary Hamilton and Wang Zhang. Berkeley and Los Angeles: University of California Press. Originally published as Xiangtu Zhongguo.

Fine, Gary Alan. 1996. Kitchens: The Culture of Restaurant Work. Berkeley and Los Angeles: University of California Press.

Gerlach, Michael. 1992. Alliance Capitalism: The Social Organization of Japanese Business. Berkeley and Los Angeles: University of California Press.

Gerlach, Michael, and James Lincoln. 1998. "Structural Analysis of Japanese Economic Organization: A Conceptual Framework." Pp. 293-321 in Networks, Markets, and the Pacific Rim, edited by Mark Fruin. New York: Oxford University Press.

Goffman, Erving. 1959. The Presentation of Self in Everyday Life. New York: Anchor, Doubleday.

- 1967. Interaction Ritual: Essays on Face-to-Face Behavior. New York: Pantheon.

$\rightarrow \longrightarrow$. 1983. "The Interaction Order: American Sociological Association, 1982 Presidential Address." American Sociological Review 48 (1): 1-17.

$\rightarrow$ Gold, Thomas. 1985. "After Comradeship: Personal Relations in China since the Cultural Revolution." China Quarterly 104:657-75.

. 1989. "Guerilla Interviewing among the Getihu." Pp. 175-92 in Unofficial China: Popular Culture and Thought in the People's Republic, edited by Perry Link, Richard Madsen, and Paul Pickowicz. Boulder, Colo.: Westview.

$\rightarrow$ Gouldner, Alvin. 1960. "The Norm of Reciprocity: A Preliminary Statement." American Sociological Review 25:161-78.

$\rightarrow$ Granovetter, Mark. 1973. "The Strength of Weak Ties." American Journal of Sociology 78:1360-80.

- 1974. Getting a Job: A Study of Contacts and Careers. Cambridge, Mass. Harvard University Press.

$\rightarrow \longrightarrow$. 1985. "Economic Action and Social Structure: The Problem of Embeddedness." American Journal of Sociology 91:481-510.

. 1990. "The Old and the New Economic Sociology: A History and an Agenda." Pp. 89-112 in Beyond the Marketplace: Rethinking Economy and Society, edited by Roger Friedland and A. F. Robertson. New York: Aldine de Gruyter.

Guseva, Alya. 2008. Into the Red: The Birth of the Credit Card Market in Postcommunist Russia. Stanford, Calif.: Stanford University Press.

$\rightarrow$ Guseva, Alya, and Akos Rona-Tas. 2001. "Uncertainty, Risk, and Trust: Russian and

750 
American Credit Card Markets Compared.” American Sociological Review 66: 623-46.

$\rightarrow$ Guthrie, Douglas. 1998. "Declining Significance of Guanxi in China's Economic Transition." China Quarterly 154:254-82. . 1999. Dragon in a Three-Piece Suit: The Emergence of Capitalism in China. Princeton, N.J.: Princeton University Press.

Hamilton, Gary. 1985. "Why No Capitalism in China? Negative Questions in Historical, Comparative Research." Journal of Developing Societies 1:187-211. . 1996. "The Theoretical Significance of Asian Business Networks." Pp. 283-98 in Asian Business Networks, edited by Gary Hamilton. New York: de Gruyter. - 1998. "Patterns of Asian Network Capitalism: The Cases of Taiwan and South Korea." Pp. 181-99 in Networks, Markets, and the Pacific Rim: Studies in Strategy, edited by Mark Fruin. New York: Oxford University Press.

Hanser, Amy. 2002. "Youth Job Searches in Urban China: The Use of Social Connections in a Changing Labor Market." Pp. 137-61 in Social Connections in China: Institutions, Culture, and the Changing Nature of Guanxi, edited by Thomas Gold, Doug Guthrie, and David Wank. New York: Cambridge University Press.

Hertz, Ellen. 2001. "Face in the Crowd: The Cultural Construction of Anonymity in Urban China." Pp. 274-93 in China Urban: Ethnographies of Contemporary Culture, edited by Nancy Chen, Constance Clark, Suzanne Gottschang, and Lyn Jeffery. Durham, N.C.: Duke University Press.

Homans, George. 1974. Social Behavior: Its Elementary Form. Rev. ed. New York: Harcourt Brace Jovanovich.

$\rightarrow$ Hwang, Kwang-kuo. 1987. "Face and Favor: The Chinese Power Game." American Journal of Sociology 92:944-74.

Ibarra, Herminia. 1992. "Structural Alignments, Individual Strategies, and Managerial Action: Elements toward a Network Theory of Getting Things Done." Pp. 165-88 in Networks and Organizations: Structure, Form, and Action, edited by Nitin Nohria and Robert Eccles. Boston: Harvard Business School Press.

Jeffery, Lyn. 2001. "Placing Practices: Transnational Network Marketing in Mainland China." Pp. 23-42 in China Urban: Ethnographies of Contemporary Culture, edited by Nancy Chen, Constance Clark, Suzanne Gottschang, and Lyn Jeffery. Durham, N.C.: Duke University Press.

Kao, Cheng-shu. 1996. "Personal Trust' in the Large Businesses in Taiwan: A Traditional Foundation for Contemporary Economic Activities." Pp. 61-70 in Asian Business Networks, edited by Gary Hamilton. New York: de Gruyter.

Krackhardt, David. 1992. "The Strength of Strong Ties: The Importance of Philos in Organizations." Pp. 216-39 in Networks and Organizations: Structure, Form, and Action, edited by Nitin Nohria and Robert Eccles. Boston: Harvard Business School Press.

$\rightarrow$ Lawler, Edward. 2001. "An Affect Theory of Social Exchange." American Journal of Sociology 107:321-52.

$\rightarrow$ Lawler, Edward, and Jeongkoo Yoon. 1998. "Network Structure and Emotion in Exchange Relations." American Sociological Review 63:871-94.

Lee, Sheng-Yi. 1990. Money and Finance in the Economic Development of Taiwan. London: Macmillan.

Leidner, Robin. 1993. Fast Food, Fast Talk: Services Work and the Routinization of Everyday Life. Berkeley and Los Angeles: University of California Press.

Lin, Nan. 2001. "Guanxi: A Conceptual Analysis." Pp. 153-66 in The Chinese Triangle of Mainland China, Taiwan, and Hong Kong, edited by Alvin So, Nan Lin, and Dudley Poston. Greenwich, Conn.: Greenwood.

Lin, Yi-min. 2002. "Beyond Dyadic Social Exchange: Guanxi and Third-Party Effects." Pp. 57-74 in Social Connections in China: Institutions, Culture, and the Changing 
American Journal of Sociology

Nature of Guanxi, edited by Thomas Gold, Doug Guthrie, and David Wank. Cambridge: Cambridge University Press.

$\rightarrow$ Lincoln, James, Michael Gerlach, and Peggy Takahashi. 1992. "Keiretsu Networks in the Japanese Economy: A Dyad Analysis of Intercorporate Ties." American Sociological Review 57:561-85.

$\rightarrow$ Macaulay, Stewart. 1963. "Non-contractual Relations in Business: A Preliminary Study." American Sociological Review 28:55-67.

Macneil, Ian. 1985. "Relational Contract: What We Do and Do Not Know." Wisconsin Law Review 1985:483-525.

$\rightarrow$ Michelson, Ethan. 2007. "Lawyers, Political Embeddedness, and Institutional Continuity in China's Transition from Socialism.” American Journal of Sociology 113 (2): 352-414.

$\rightarrow$ Mizrachi, Nissim, Israel Drori, and Renee Anspach. 2007. "Repertories of Trust: The Practice of Trust in a Multinational Organization amid Political Conflict." American Sociological Review 72:143-65.

$\rightarrow$ Molm, Linda, Jessica Collett, and David Schaefer. 2007. "Building Solidarity through Generalized Exchange: A Theory of Reciprocity." American Journal of Sociology 113:205-42.

$\rightarrow$ Molm, Linda, Gretchen Peterson, and Nobuyuki Takahashi. 1999. "Power in Negotiated and Reciprocal Exchange." American Sociological Review 64:876-90.

$\rightarrow$ Molm, Linda, Nobuyuki Takahashi, and Gretchen Peterson. 2000. "Risk and Trust in Social Exchange: An Experimental Test of a Classical Proposition." American Journal of Sociology 105:1396-1427.

Nee, Victor, and Paul Ingram. 1998. "Embeddedness and Beyond: Institutions, Exchange, and Social Structures." Pp. 19-45 in The New Institutionalism in Sociology, edited by Mary Brinton and Victor Nee. New York: Russell Sage Foundation.

Numazaki, Ichiro. 1996. "The Role of Personal Networks in the Making of Taiwan's Guanxiqiye (Related Enterprise)." Pp. 71-86 in Asian Business Networks, edited by Gary Hamilton. New York: de Gruyter.

Oakes, Guy. 1990. The Soul of the Salesman: The Moral Ethos of Personal Sales. Atlantic Highlands, N.J.: Humanities Press.

$\rightarrow$ Peng, Yusheng. 2004. "Kinship Networks and Entrepreneurs in China's Transitional Economy." American Journal of Sociology 109:1045-74.

$\rightarrow$ Podolny, Joel, and James Baron. 1997. "Resources and Relationships: Social Networks and Mobility in the Workplace." American Sociological Review 62:673-93.

Portes, Alejandro, Manuel Castells, and Lauren A. Benton, eds. 1989. The Informal Economy: Studies in Advanced and Less Developed Countries. Baltimore: Johns Hopkins University Press.

Powell, Walter. 1985. Getting into Print: The Decision-Making Process in Scholarly Publishing. Chicago: University of Chicago Press.

Powell, Walter, and Laurel Smith-Doerr. 1994. "Networks and Economic Life." Pp. 368-402 in the Handbook of Economic Sociology, edited by Neil J. Smelser and Richard Swedberg. Princeton, N.J.: Princeton University Press.

Ragin, Charles. 1994. Constructing Social Research. Thousand Oaks, Calif.: Pine Forge Press.

$\rightarrow$ Raub, Werner, and Jeroen Weesie. 1990. "Reputation and Efficiency in Social Interactions: An Example of Network Effects.” American Journal of Sociology 96:626-54.

Romo, Frank, and Michael Schwartz. 1995. "The Structural Embeddedness of Business Decisions: The Migration of Manufacturing Plants in New York State, 1960 to 1985." American Sociological Review 66:382-403.

Sako, Mari. 1992. Price, Quality and Trust: Inter-firm Relations in Britain and Japan. Cambridge: Cambridge University Press.

$\rightarrow$ Sako, Mari, and Susan Helper. 1998. "Determinants of Trust in Supplier Relations: 
Life Insurance Transactions in China

Evidence from the Automotive Industry in Japan and the United States.” Journal of Economic Behavior and Organization 34:387-417.

$\rightarrow$ Schneiberg, Marc, and Elisabeth Clemens. 2006. "The Typical Tools for the Job: Research Strategies in Institutional Analysis.” Sociological Theory 24:195-227.

$\rightarrow$ Stinchcombe, Arthur. 1990. "Weak Structural Data (Review of Mizruchi and Schwartz)." Contemporary Sociology 19:380-82

$\rightarrow$ Swedberg, Richard. 1997. "New Economic Sociology: What Has Been Accomplished, What Is Ahead?" Acta Sociologica 40:161-82.

$\rightarrow$ Swidler, Ann. 1986. "Culture in Action: Symbols and Strategies." American Sociological Review 51:273-86.

Tang, Wenfang. 2005. "Interpersonal Trust and Socio-Political Change.” Pp. 101-17 in Public Opinion and Political Change in China, edited by Wenfang Tang. Stanford, Calif.: Stanford University Press.

$\rightarrow$ Uzzi, Brian. 1996. "The Sources and Consequences of Embeddedness for the Economic Performance of Organizations: The Network Effect." American Sociological Review 61:674-98

$\rightarrow$. 1997. "Social Structure and Competition in Interfirm Networks: The Paradox of Embeddedness." Administrative Science Quarterly 42:35-67.

$\rightarrow \longrightarrow$. 1999. "Embeddedness in the Making of Financial Capital: How Social Relations and Networks Benefit Firms Seeking Financing." American Sociological Review 64:481-505.

$\rightarrow$ Uzzi, Brian, and Ryon Lancaster. 2003. "Relational Embeddedness and Learning: The Case of Bank Loan Managers and Their Clients." Management Science 49 (4): 383-99.

$\rightarrow$. 2004. "Embeddedness and the Price of Legal Services." American Sociological Review 69 (3): 319-44.

Velez-Ibanez, Carlos. 1983. Rituals of Marginality: Politics, Process, and Culture Change in Urban Central Mexico, 1969-1974. Berkeley and Los Angeles: University of California Press.

Walder, Andrew. 1986. Communist Neo-Traditionalism: Work and Authority in Chinese Society. Berkeley and Los Angeles: University of California Press.

$\rightarrow$ Wank, David. 1996. "The Institutional Process of Market Clientalism: Guanxi and Private Business in a South China City." China Quarterly 147:820-38.

_. 2002. "Business-State Clientelism in China: Decline or Evolution?" Pp. 97-116 in Social Connections in China: Institutions, Culture, and the Changing Nature of Guanxi, edited by Thomas Gold, Doug Guthrie, and David Wank. New York: Cambridge University Press.

Watts, Duncan, and Steven Strogatz. 1998. "Collective Dynamics of Small-World Networks." Nature 363:202-4.

Wellman, Barry. 1999. "The Network Community." Pp. 1-48 in Networks in the Global Village, edited by Barry Wellman. Boulder, Colo.: Westview.

Wellman, Barry, Wenhong Chen, and Weizhen Dong. 2002. "Networking Guanxi." Pp. 221-41 in Social Connections in China: Institutions, Culture, and the Changing Nature of Guanxi, edited by Thomas Gold, Doug Guthrie, and David Wank. Cambridge: Cambridge University Press.

$\rightarrow$ Wellman, Barry, and Scot Wortley. 1990. "Different Strokes from Different Folks: Community Ties and Social Support." American Journal of Sociology 96:558-88.

$\rightarrow$ White, Harrison. 1981. "Where Do Markets Come From?" American Journal of Sociology 87:517-47.

. 1992. Identity and Control. Princeton, N.J.: Princeton University Press.

Wong, Siu-lun. 1996. "Chinese Entrepreneurs and Business Trust." Pp. 13-26 in Asian Business Networks, edited by Gary Hamilton. New York: de Gruyter.

$\rightarrow$ Wong, Siu-lun, and Janet Salaff. 1998. "Network Capital: Emigration from Hong Kong." British Journal of Sociology 49:358-74. 


\section{American Journal of Sociology}

Wu, Shen Yuan, and Wen Yu Zheng. 1993. Zhongguo baoxian shihua (Talking about the history of insurance in China). Beijing: Economics Management Publisher.

Yan, Yunxiang. 1996. The Flow of Gifts: Reciprocity and Social Networks in a Chinese Village. Stanford, Calif.: Stanford University Press.

Yang, Mayfair Mei-hui. 1994. Gifts, Favors, and Banquets: The Art of Social Relationships in China. Ithaca, N.Y.: Cornell University Press.

Zelizer, Viviana. 1979. Morals and Markets: The Development of Life Insurance in the United States. New York: Columbia University Press.

$\rightarrow$ - 1988. "Beyond the Polemics on the Market: Establishing a Theoretical and Empirical Agenda." Sociological Forum 3:614-34.

$\rightarrow \longrightarrow$. 1996. "Payments and Social Ties." Sociological Forum 11:481-95.

2005. The Purchase of Intimacy. Princeton, N.J.: Princeton University Press.

$\rightarrow$ Zhao, Dingxin. 1998. "Ecologies of Social Movements: Student Mobilization during the 1989 Prodemocracy Movement in Beijing." American Journal of Sociology 103: $1493-1529$.

Zukin, Sharon, and Paul DiMaggio. 1990. "Introduction." Pp. 1-36 in Structures of Capital: The Social Organization of the Economy, edited by Sharon Zukin and Paul DiMaggio. New York: Cambridge University Press. 